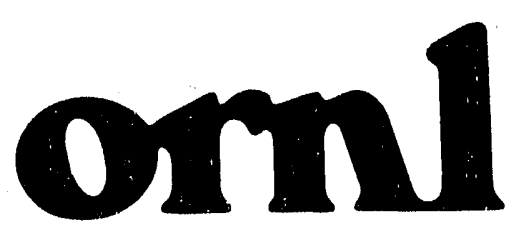

OAK RIDGE NATIONAL LABORATORY

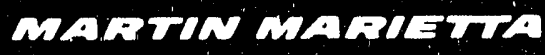

ORNL/TM--11508

DE91 000549
Atmospheric Dispersion Modeling and Meteorological Monitoring in Support of Emergency Planning and Response for the U.S. Army's

Chemical Stockpile Disposal Program

R. L. Miller

MARTIN MARIETTA ENERGY SYSTEMS, IIIC.

FOR THE INITTEO STATFS

DEPARTMENT OF ENERGY 
This report has been reproduced directly from the best available copy.

Available to DOE and DOE contractors from the Office of Scientific and Technical information, P.O. Box 62, Oak Ridge, TN 37831; prices available from (615) 576-8401, FTS 626-8401.

Available to the public from the National Technical Information Service, U.S. Department of Commerce, 5285 Port Royal Rd., Springfield, VA 22161.

NTIS price codes-Printed Copy: A04 Microfiche AO1

This report was prepared as an account of work sponsored by an agency of the United States Government. Neither the United States Government nor any agency thereof, nor any of their employees, makes any warranty, express or implied, or assurnes any legal liability or responsibility for the accuracy, completeness, or usefulness of any information, apparatus, product, or process disclosed, or represents that its use would not infringe privately owned rights. Reterence herein to any specific commercial product, process, or service by trade name, trademark, manufacturer, or otherwise, does not necessarily constitute or imply its endorsement, recor,umendation, or favoring by the United States Government or any agency therirof. The views and opinions of authors expressed herein do not necessarily state or reflect those of the United States Government or any agency therecf. 
Energy Division

\section{ATMOSPHERIC DISPERSION MODELING AND METEOROLOGICAL MONITORING IN SUPPORT OF EMERGENCY PLANNING AND RESPONSE FOR THE U.S. ARMY'S CHEMICAL STOCKPILE DISPOSAL PROGRAM}

R. L. Miller

Date Published-August 1990

Prepared for the

U.S. Department of the Army

under Interagency Agreement 1457-B106-A

Prepared by the

OAK RIDGE NATIONAL LABORATORY

Oak Ridge, Tennessee 37831

operated by

MARTIN MARIETTA ENERGY SYSTEMS, INC.

for the

U.S. DEPARTMENT OF ENERGY

under Contract No. DE-AC05-84OR21400

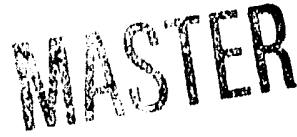




\section{CONTENTS}

LIST OF FIGURES $\ldots \ldots \ldots \ldots \ldots \ldots \ldots \ldots \ldots \ldots \ldots \ldots$

LIST OF TABLES $\ldots \ldots \ldots \ldots \ldots \ldots \ldots \ldots \ldots \ldots \ldots \ldots \ldots$ vii

ACRONYMS AND ABBREVIATIONS $\ldots \ldots \ldots \ldots \ldots \ldots \ldots \ldots \ldots$ ix

ABSTRACT $\ldots \ldots \ldots \ldots \ldots \ldots \ldots \ldots \ldots \ldots \ldots \ldots \ldots \ldots \ldots \ldots$

1. INTRODUCTION $\ldots \ldots \ldots \ldots \ldots \ldots \ldots \ldots \ldots \ldots \ldots \ldots$

2. BACKGROUND OF EMERGENCY PLANNING FOR THE CSDP . . . . . 3

3. AN INTEGRATED APPROACH TO EMERGENCY RESPONSE . . . . . . 7

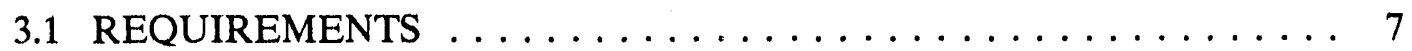

3.2 OPERATIONAL STATE-OF-THE-ART SYSTEMS $\ldots \ldots \ldots \ldots \ldots 7$

4. ATMOSPHERIC DISPERSION MODELING FOR

EMERGENCY RESPONSE . . . . . . . . . . . . . . . . . 11

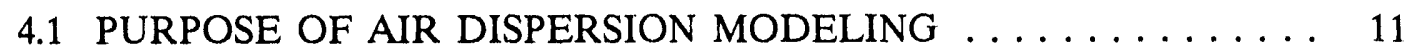

4.2 TYPES OF AIR DISPERSION MODELS . . . . . . . . . . . . 11

4.3 CRITERIA FOR SELECTION OF AN AIR

DISPERSION MODEL $\ldots \ldots \ldots \ldots \ldots \ldots \ldots \ldots \ldots \ldots \ldots$

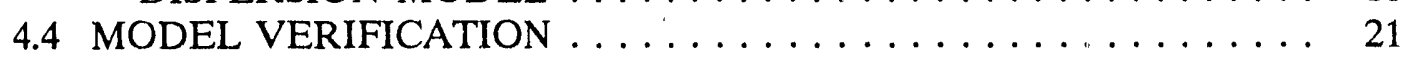

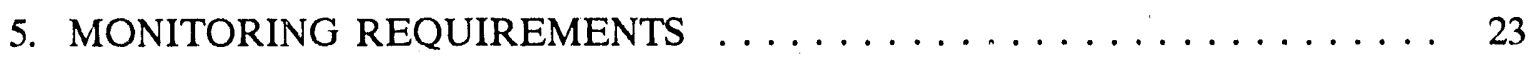

5.1 METEOROLOGICAL MONITORING .............. 23

5.2 AGENT MONITORING .................. 26

6. PERSONNEL REQUIREMENTS $\ldots \ldots \ldots \ldots \ldots \ldots \ldots \ldots \ldots \ldots$

7. SITE-SPECIFIC REQUIREMENTS AND CAPABILITIES . . . . . . . . . . 29

8. SUMMARY AND RECOMMENDATIONS $\ldots \ldots \ldots \ldots \ldots \ldots \ldots$

9. FUTURE WORK $\ldots \ldots \ldots \ldots \ldots \ldots \ldots \ldots \ldots \ldots \ldots \ldots \ldots$

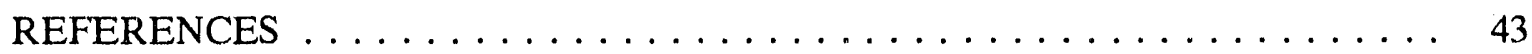




\section{LIST OF FIGURES}

1. Locations of the eight U.S. Army installations which store existing chemical agents and munitions in the continental United States . . . . . . . 4

2. Relationships among components of the integrated accident assessment

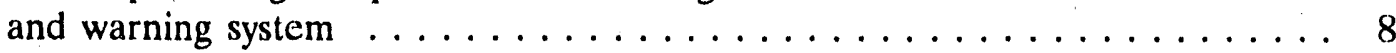

3. Diagram illustrating that information on puff or plume diffusion is dependent on sampling time and travel time . . . . . . . . . . 14

4. Illustration of shoreline fumigation $\ldots \ldots \ldots \ldots \ldots \ldots \ldots \ldots \ldots \ldots$ 


\section{LIST OF TABLES}

1. Local geographical features and their effects on meteorology at the Chemical Stockpile Disposal Program installations . . . . . . . . . . . 30

2. Estimated population around the Chemical Sockpile Disposal Program installations

3. Existing meteorological monitoring and air dispersion modeling capabilities 


\section{ACRONYMS AND ABBREVIATIONS}

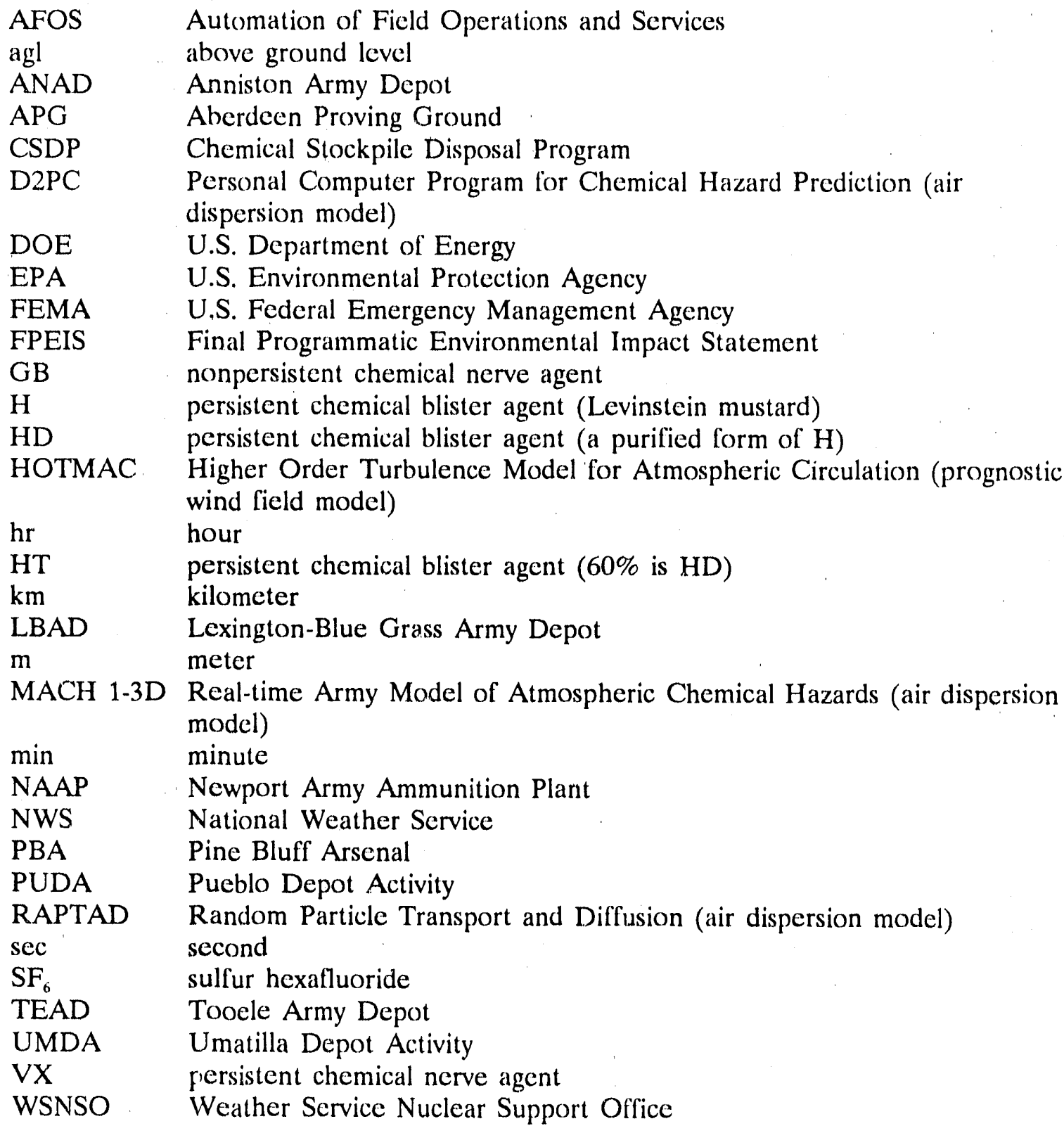




\begin{abstract}
This technical memorandum examines the role of atmospheric dispersion modeling and metcorological monitoring in support of emergency planning and response for the U.S. Army's Chemical Stockpile Disposal Program (CSDP). Air dispersion modeling and meteorological monitoring are expected to form key components in integrated accident assessment and warning systems at each of the cight CSDP installations. This report assesses the capabilities of operating state-of-the-art systems in order to establish a baseline for developing the requirements of the CSDP systems. A general tutorial on the types of atmospheric dispersion models currently available is provided, and the criteria for selection of emergency response models are developed. The requirements for meteorological monitoring are also described. In addition, the basic limitations of modeling and monitoring are discussed, and the importance of model verification is emphasized. Staffing requirements to operate an integrated modeling and monitoring system are characterized.

The current state of modeling, monitoring, and staffing levels in support of emergency response at the eight U.S. Army chemical stockpile depots involved in the CSDP is examined. Specific requirements appropriate to emergency planning and response at each of the eight sites are described. Recommendations are made for both the integrated system and the individual components of air dispersion modeling and meteorological monitoring. Finally, future work required to prepare for emergency response is discusset.
\end{abstract}




\section{INTRODUCTION}

The effectiveness of emergency response in the event of an accidental release of chemical agent during the U.S. Department of the Army's Chemical Stockpile Dis zosal Program (CSDP) depends on many critical technical, organizational, and human-response factors. Successful emergency response requires top-quality instrumentation, hardware, and other equipment; well-conceived and -implemented computer programs; competent, highly trained personnel capable of making decisions quickly; and well-established lines of communication among appropriate organizations and the public. Equipment is required for vital functions such as monitoring process conditions for detection of abnormalities or upsets, detecting concentrations of chemical agent in the air, characterizing the atmospheric environment into which an accidental release is emitted, running computer programs that assist in decision-making, and providing physical protection from adverse health effects due to a release. Computer programs are essential for assembling, analyzing, and disseminating information and assisting in selecting and enacting protective action. The probability of successful emergency response is maximized by well-trained personnel that can make informed decisions promptly. Lines of communication, both from a technical and organizational perspective, are critical for decision-making and warning the potentially affected population. These key components must be fused into an integrated accident assessment and warning system to permit timely decisions that would enable sufficient warning and protective response to an accident.

Timely decision-making is crucial to emergency response programs. For example, at several CSDP sites, residents live within a few kilometers of the existing chemical storage areas and/or proposed disposal facilities; and for some meteorological conditions, accidental relcases could result in dangerous concentrations of chemical agent beyond the installation boundary within a few minutes. A very fast response time is required to permit protective action by these affected residents. The maximum allowable time to make initial decisions after an accidental release is between 5 and 10 min (Chester 1989; Feldman and Dobson 1990).

Atmospheric dispersion modeling and meteorological monitoring are fundamental components of an integrated accident assessment and warning system. Air dispersion models calculate concentrations and/or doses expected downwind of an accidental release to predict potential consequences from an accident prior to the arrival of agent downwind. Dose, as used in this study, is defined as the in igration of agent concentration over the duration of exposure (effectively, the multiplicative product of average concentration and time of exposure). Meteorological monitoring characterizes the atmospheric environment (e.g., wind direction and speed) into which an accidental release would enter.

As one of the CSDP technical support studies completed for emergency planning, this report examines the purpose of and develops requirements for atmospheric 
dispersion modeling and meteorological monitoring in support of an integrated accident assessment and warning system. A review is performed to assess the capabilities of operating state-of-the-art systems and establish a baseline for developing the requirements of the CSDP system. A general $t$ :orial on the types of atmospheric dispersion models currently available is provided, and the criteria for selection of emergency response models are developed. The general requirements for meteorological monitoring are also described. In addition, the basic limitations of modeling and monitoring are discussed, and the importance of model verification is emphasized. Staffing requirements to operate an integrated modeling and monitoring system are characterized. A brief discussion of agent monitoring, an important component of the integrated system, also is included. Although process monitoring to detect upset conditions that may indicate an accidental release should be included in the integrated system, a discussion of process monitoring is beyond the scope of this study.

A review is conducted of current modeling, monitoring, and staffing levels in support of emergency response at the eight U.S. Army chemical stockpile depots involved in the CSDP. Specific requirements germane to emergency planning and response at each of the eight sites are described. Recommendations are made for both the integrated system and the individual components of air dispersion modeling and meteorological monitoring. Finally, additional work required in the future to prepare for emergency response is discussed.

Other CSDP technical support studies associated with the integrated accident assessment and warning system evaluate accident assessment (Chester 1989), decisionmaking (Feldman and Dobson 1990), protective action (Rogers et al. 1989), and sitespecific emergency response concept plans (Carnes 1989). The cumulative counsel of these documents should be considered in the formulation and implementation of an intcgrated system. 


\section{BACKGROUND OF EMERGENCY PLANNING FOR THE CSDP}

The Army proposes under the CSDP to destroy the nation's total stockpile of lethal unitary chemical agents and munitions, which include nerve agents that directly affect the nervous system (e.g., GB and VX), and blister agents that produce blisters on exposed issue (e.g., H, HD, and HT). Unitary agents are so named because they can produce a hazardous effect on human health in their form as stored; they do not require mixing with another component to become hazardous (as is the case with binary chemical agents). The agents are stored in munitions (rockets, land mines, mortars, cartridges, and projectiles) that contain not only agents but also various explosive components (fuses, propellants, and bursters), or are stored in bulk containers (bombs, spray tanks, and steel 1-ton containers), none of which contains any explosives.

The CSDP is being carried out in response to a congressional mandate in Title 14 , Part B, Section 1412 of Public Law 99-145, the Department of Defense Authorization Act of 1986, which directs that the destruction of the agents and munitions be accomplished by September 30, 1994, in conjunction with the acquisition of binary chemical weapons. In September 1988, the Army received an extension from Congress of the 1994 deadline to April 30, 1997, under Public Law 100-456.

As depicted in Fig. 1, the existing chemical munitions stored in the continental United States are located at eight U.S. Army installations: Aberdeen Proving Ground (APG), near Edgewood, Maryland; Anniston Army Depot (ANAD), near Anniston, Alabama; Lexington-Blue Grass Army Depot (LBAD), near Lexington, Kentucky; Newport Army Ammunition Plant (NAAP), near Newport, Indiana; Pine Bluff Arsenal (PBA), ncar Pine Bluff, Arkansas; Pueblo Depot Activity (PUDA), near Pueblo, Colorado; Toocle Army Depot (TEAD), near Tooele, Utah; and Umatilla Depot Activity (UMDA), near Hermiston, Oregon. None of the agents and munitions currently in storage has been manufactured since 1968 and the condition of some has deteriorated.

At each of the eight sites, the Army proposes to remove the agents and munitions from existing storage, transport them to a proposed on-site disposal facility, disassemble them, and incinerate the agents; no stockpiled agents or munitions are proposed to be transported to other storage installaticns or sites for destruction. In compliance with the National Environmental Policy Act, the Army issued a Final Programmatic Environmental Impact Statement (FPEIS) (U.S. Army 1988) in January 1988 that discussed five alternatives for destroying the stockpile (no action, on-site disposal, and three transportation alternatives) and identified on-site disposal as the environmentally preferred alternative. In February 1988, the Army's Record of Decision for the FPEIS selected on-site disposal for implementation.

The Army and the U.S. Federal Emergency Management Agency (FEMA) signed a Memorandum of Understanding in August 1988 to establish a framework of cooperation 


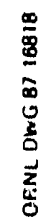

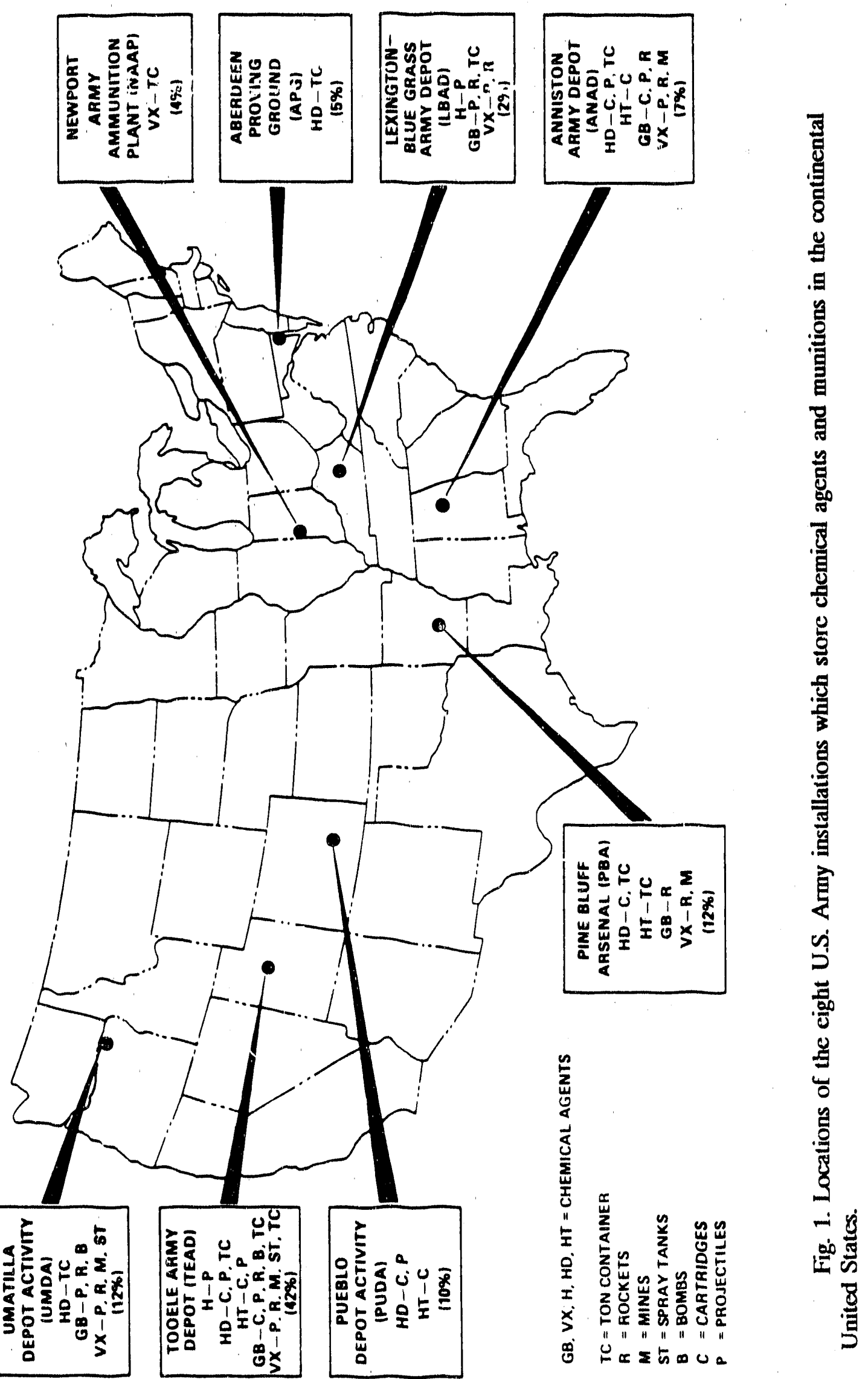


to identify their respective roles and responsibilities for emergency preparedness involving the strrage and disposal of chemical agents and munitions and to establish joint program efforts in emergency planning, training, and information exchange (Carnes 1989). With the assistance of FEMA, other federal agencies, and contractor organizations, the Army is upgrading the off-site or civilian emergency plans at each installation, analyzing training requirements, evaluating communication system needs, and studying warning system requirements. The overall CSDP emergency planning and preparedness program is scheduled to run from January 1987 tn December 1998 when the disposal of the chemical stockpile has been completed.

The SSDP emergency planning and preparedness program is guided by three fundamental objectives: prevention of human fatalities, community participation, and equitable distribution of resources among CSDP sites (Carnes 1989). Because the first objective is the most important, decisions should be based on concern for public safety whenever feasible. The goal of community participation is to involve the affected citizens in the plannirig process so that the program is publicly acceptable and workable. Finally, although each site has different needs and may opt for different approaches to emergency preparedness, the allocation of resources should not be biased toward any given site. The equitable distribution of resources should also contribute to public acceptance of the program. 


\section{AN INTEGRATED APPROACH TO EMERGENCY RESPONSE}

\subsection{REQUIREMENTS}

Because of the extremely toxic nature of the chemical agents and very fast response time required to permit protective action, an integrated accident assessment and warning system is crucial to the success of the CSDP. In the event of an accidental release, the system is required to function proficiently and quickly to provide information on the nature and severity of the accident to decision-makers. For example, decision-makers need to know the timing of the release and potential for off-site consequences so they can determine the necessity for and geographical extent of protective action. Key components of the system must include atmospheric dispersion modeling, meteorological monitoring, monitoring of chemical agent, and competent, trained personncl familiar with the system. These components must be compatible with other components such as decisir assisting software, warning and protective action in response to an accident, and comrinunication lines. Therefore, an interdisciplinary team is needed to develop the system to ensure that all components are considered thoroughly and that integration of the components results in an effective system. Figure 2 illustrates relationships among the components of an operational system.

A key requirement of an iritegrated accident assessment and warning system is that it should be developed centrally rather than by different groups at each of the installations. Although the system should be flexible enough to allow for site-specific differences and an independent operating system should be located at each of the installations, the overall design and implementation should be centralized to ensure that cumulative knowledge and creati ity are being applied to the development of the system and that some uniformity results in the operating systems at the installations. Otherwise, eight different systems with varying degrees of capability will evolve. The tremendous variation in current accident assessment and warning systems at the CSDP installations reflects this concern. Of course, personnel from each of the installations should be part of the team developing the system to ensure that site-specific concerns are addressed adequately. Input from local agencies and organizations is also vital so that features of importance to these groups can be considered for the system.

\subsection{OPERATIONAL STATE-OF-THE-ART SYSTEMS}

A revicw of operational state-of-the-art integrated accident assessment and warning systems was conducted to assist in defining requirements for the CSDP system and determining the feasibility of incorporating desirable features into an operational system. After an initial screening review, the scope was narrowed to the meteorological components of systems developed by the private sector for use at facilities such as chemical manufacturing plants and oil refineries, and those developed at U.S. Department of Energy (DOE) facilicies which produce and/or handle nuclear materials 


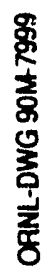

尊

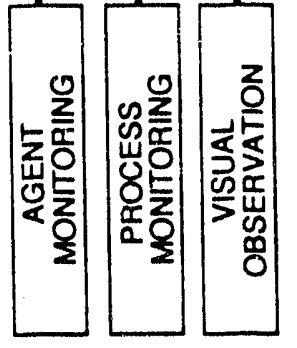

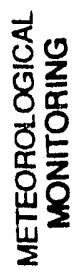


for defense purposes. The former systems usually consist of standard packages developed by private companies that can be tailored for specific facilities, while the latter systems usually are customized packages developed on-site at each of the DOE facilities.

Many air dispersion models have been developed by the private sector for emergency preparedness and response. A large portion of these models evolved from spill models that compute the percentage of chemical agent from a spill that evaporates into the atmosphere; subsequently, the models calculate the transport and diffusion of the airborne agent downwind. Operational state-of-the-art systems have become quite sophisticated. Features that are available with current systems include user-friendly, metiu-driven air dispersion models that estimate the trajectory and magnitude of plumes or puffs from accidental releascs using real-time meteorological data; the amount released can be selected from a pre-established database that contains amounts expected for specific sources; the sources can be elevated or at ground level; the relcases can be instantaneous or continuous; multiple meteorological towers can be used to obtain wind fields in which the wind is allowed to change in space and time; the effects of complex terrain are included; the results are displayed on a color graphics monitor with the plume or puff superimposed on a map background; and printers and plotters make hardcopies of the results.

Many DOE facilities have sophisticated integrated accident assessment and warning systems. Generally, the features described above are also applicable at DOE facilities, and many of the facilities have additional and/or enhanced features. Those facilities with fully-developed and operational emergency response systems include the Rocky Flats Plant near Denver, Colorado; the Hanford Site near Richland, Washington; the Savannah River Plant near Aiken, South Carolina; and the Nevada Test Site near Las Vegas, Nevada (EPA and DOE 1986, DOE 1987).

One important feature at the latter three sites is the availability of current meteorological observations, anclyses, and forecasts from the National Weather Service (NWS) via the Automation of Field Operations and Services (AFOS) network. This data link couples the three facilities with the Weather Service Nuclear Support Office (WSNSO) in Las Vegas, which in turn is linked with the National Meteorological Center in Washington, D.C. to provide the facilities with all the information that is available at NWS stations. Thus, numerical weather torecasts and data from local, regional, and national stations are available to assist in emergericy planning and response at the three sites. The Rocky Flats Plant, although not in the AFOS network, has access to data from 22 real-time monitoring stations that are part of the NWS's experimental Prototype Regional Observing and Forecasting Service that is being tested in the Denver area. Wind, temperature, precipitation, solar radiation, and pressure data from these stations are transmitted to the plant at 5-minute intervals. In addition, the plant subscribes to a private service to obtain much of the weather data available from AFOS.

Unlike at many of the chemical plants, meteorulogists trained in emergency planning and response are employed at the DOE facilities to enhance the system and interpret the results. At the Rocky Flats Plant, for example, the meteoroingist on duty may 
modify the plume trajectory predicted by the mudel because of forecast wind field changes based on data from the National Weather Service. The meteorologist also prepares for decision-makers a weather forecast specific to the emergency. At the Hanford Site, the meteorologist on duty continually monitors meteorological conditions and adjusts, as necessary, files containing wind forecasts that are used as input to the air dispersion model. Altogether, the Hanford Site is staffed with seven meteorologists to maintain operations 24 hours per day, 365 days per year. Based on their training and experience, meteorologists are able, if necessary, to alter the forecasts predicted by air dispersion models and thus provide an added dimension to the integrated accident assessment and warning system. 


\section{A.TMOSPHERIC DISPERSION MODELING FOR EMERGENCY RESPONSE}

\subsection{PURPOSE OF AIR DISPERSION MODELING}

Atmospheric dispersion modeling forms a critical component in the integrated accident assessment and warning system required for emergency planning and response. For this type of application, air dispersion models calculate concentrations and/or doses expected downwind of an accidental release based on the initial amount of agent, type of release, and atmospheric conditions such as wind direction, wind speed, and atmospheric stability. Results from the models provide the areal extent and timing of ground-level concentrations and/or doses.

Modcling is necessary to forecast potential consequences from an accident prior to the arrival of agent downwind. Predictions from models are important not only at the time of an accident but also before an accident to prepare for a broad range of potential scenarios. Models play a key role in developing a methodology for emergency response and provide results for postulated scenarios that can be used in training activities. Without air dispersion modeling, predictive capability would be limited to educated estimates by personnel based on the size and type of accident and atmospheric conditions. These predictions may greatly overestimate or underestimate the downwind dose expected from a release, resulting in needless protective action or additional risk to public safety, respectively. In addition, with no modeling, the vast uncertainty regarding the path of the puff or plume from an accidental release would necessitate protective action for a larger number of people because of the wide arc of potential danger; consequently, in the event of evacuation, the selection of a safe upwind area might be difficult and the roads surrounding an installation may be extremely congested. Other options for tracking a relcase, such as relying exclusively on meteorological and agent monitoring located between the site of an accident and downwind population centers, are unacceptable from the perspective of both accuracy and timeliness. For example, under certain types of releases and atmospheric conditions, the plume or puff may not be detected by such monitors because it is elevated or narrow enough to pass between monitors.

Although model results are known to contain large inaccuracies (EPRI 1985), especially for areas with complex terrain or land/sea boundaries, reasonable estimates can be provided to assist in decision-making. For example, although some EPA-approved models are acknowledged to overpredict concentrations in complex terrain by factors of 10 to 20 , model results are typically accurate to within a factor of five, and better accuracy is possible by fine-tuning models for specilic sites and atmospheric conditions.

\subsection{TYPES OF AIR DISPERSION MODELS}

Atmospheric dispersion models generally consist of two components or modules for computing downwind concentrations and/or doses. The first component determines the 
wind field, which in turn determines the path of the mean transport of chemical agent from the source of the release to downwind locations. The second component calculates the diffusion of agent (the mixing caused by the turbulent motions of small eadies) that dilutes the agent in the horizontal and vertical directions as it travels downwind. This section provides an overview of wind field and diffusion modules currently available.

The simplest type of wind field model, which is used by the majority of air dispersion models for emergency response, assumes that the wind which transports the agent downwind is unchanging with time and space. The wind field is therefore both fixed and uniform. Although this is a reasonable assumption for small accidents with consequences that are limited in time and space, some potential accidents associated with the CSDP may cause fatalities at distances approaching $100 \mathrm{~km}$ over periods of approximately $24 \mathrm{hr}$ (U.S. Army 1988). Over such distances and time periods, factors such as changing synoptic-scale (large-scale) flow, topographical influences, and diurnal variations in local flow cause dramatic changes in the wind field. Therefore, the assumption of uniform, persistent winds for emergency response modeling for the CSDP can lead to enormous errors.

More sophisticated models are capable of incorporating data from multiple locations to develop a wind field that is reasonably accurate at the observation time. The accuracy of these models is highly dependent on the siting and number of instruments from which the models construct the wind field. These models allow the wind to change with location, but they assume that the wind field is steady-state (unchanging with time at each location). Therefore, the path of a plume or puff from an accident is based on an unchanging wind field during the period of concern. This assumption is poor for periods subject to substantial change, either from changes in synoptic-scale flow (e.g., cold frontal passage) or from local effects such as flow reversal in valleys during the transition between day and night.

In terms of accuracy, advanced models capable of forecasting future wind fields (prognostic models) are an improvement over models that assume uniform persistent winds or steady-state wind fields. Many of the prognostic models are capable of incorporating the effects of topography and vegetation; in addition, most of these models use data from surrounding National Weather Service stations in order to include changes in synoptic-scale flow in the forecasts (Yamada et al. 1989). Unfortunately, because relatively long times are required to perform the computations to predict the wind fields (e.g., the execution time using a desktop computer is appioximately 30 to $60 \mathrm{~min}$ for the HOTMAC model developed by Los Alamos National Laboratory), prognostic models currently are not being applied to state-of-the-art integrated accident assessment and warning systems. In an emergency response situation, the usefulness of the model is extremely limited if model execution is not quick enough to provide results that authorities can employ in making decisions. However, because prognostic models have predictive capability, results from these models are not as likely to be out-of-date as quickly as results from the other models. For example, the prognostic models should be able to predict flow reversal in valleys after sunrise, whereas other models are dependent on actual observations documenting the occurrence of flow reversal before they account for it. 
The second module of an air dispersion model calculates the diffusion of agent in the horizontal and vertical directions as it travels doivnwind. The Gaussian model is the best known and most commonly used type of diffusicn model (EPA 1986). The development of models that use a Gaussian distribution of a substance in the vertical and cross-wind directions as the substance disperses downwind has been documented extensively in the literature (Sutton 1932; Gifford 1968; Pasquill 1974), and most models still use a Gaussian distribution because (Hanna et al. 1982)

1. it produces results that agree with experimental data as well as any model;

2. its basic equation allows mathematical operations to be performed fairly easily;

3. it is appealing conceptually;

4. it is consistent with the random nature of thirbulence;

5. other so-called theoretical formulas are substantially empirical in their final stages; and

6. as a result of the above reasons, it is accepted by the U.S. Environmental Protection Agency (EPA 1986) and is used by many government agencies.

Depending on the duration of a release, the sampling time, and travel time, a Gaussian diffusion model may be formulated to calculate concentrations and/or doses as a puff or plume model. Puff diffusion formulas apply to instantaneous sources, where the release time or sampling time is short compared with the travel time from source to receptor. With a relatively short sampling time, only a "snapshot" of the characteristics of a release can be obtained. Puff models can be used to represent a relatively longterm release under these conditions by assuming a series of puffs with dispersion characteristics that are functions of time and stability. Plume diffusion formulas apply to continuous plumes, where the release and sampling times are long compared with the travel time. A more complete characterization of a plume is possible with a relatively long sampling time. When the travel time is approximately equal to the sampling and release times, a combination of puff and plume diffusion techniques may be necessary (Hanna et al. 1982).

Figure 3 provides an example in which a single plume can actually be considered to give information on puff diffusion, plume diffusion, and a combination of the two (Hanna et al. 1982). In this case, it is assumed that multiple aircraft measure the plume in lateral traverses at different distances downwind, with each aircraft making multiple passes at the same downwind distance over a total sampling time of $1 \mathrm{hr}$. Because the wind speed is assumed to be $5 \mathrm{~m} / \mathrm{sec}$, the plume covers a distance of $18 \mathrm{~km}$ in $1 \mathrm{hr}$. Therefore, at this distance downwind of the source, the travel time is equal to the sampling time and a combination of puff and plume characteristics is oblained. For downwind distances less than about $10 \mathrm{~km}$, aireraft measurements provide information regarding continuous plume diflusion. For downwind distances greater than about $30 \mathrm{~km}$, the measurements yield information more appropriate to pulf diflusion. 

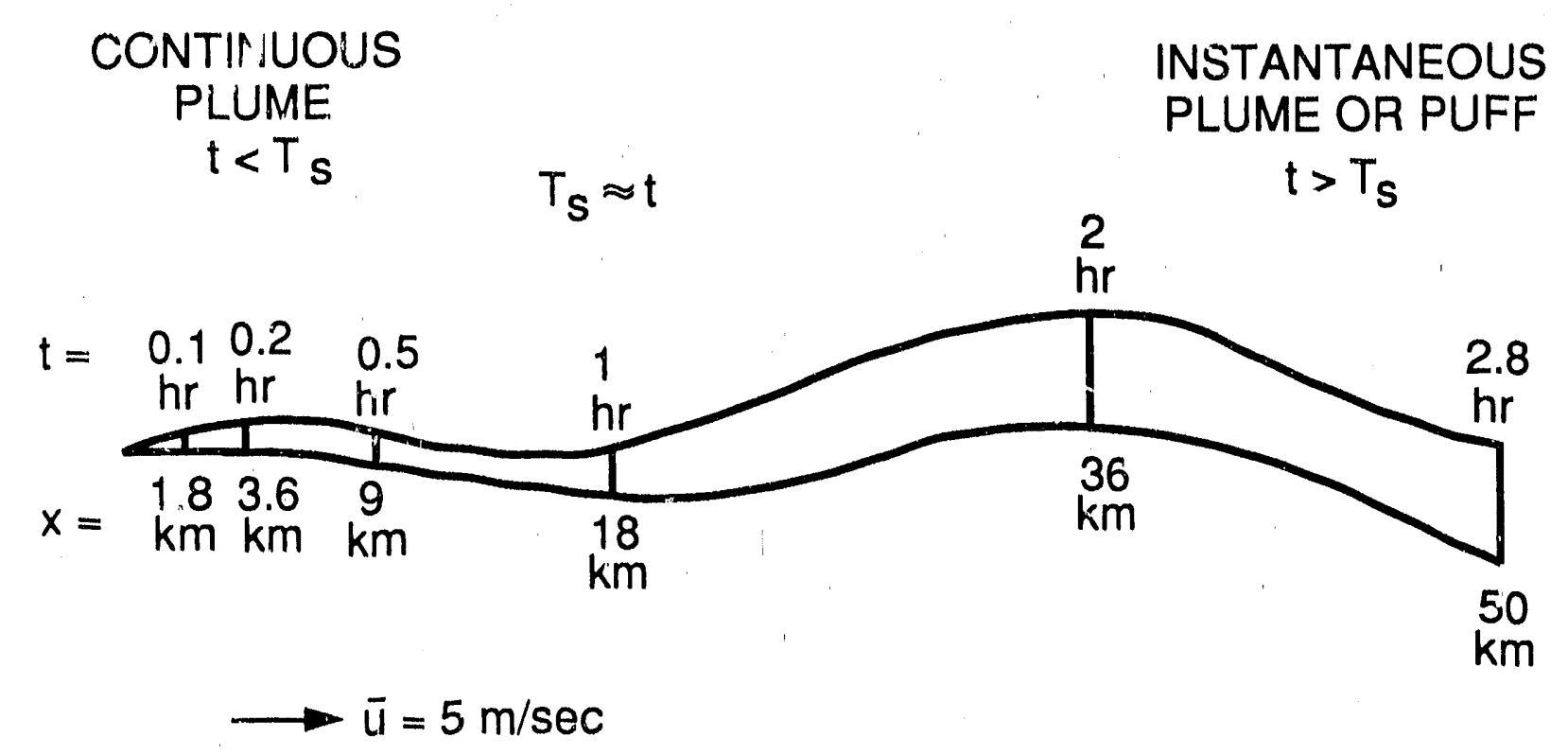

Fig. 3. Diagram illustrating that information on puff or plume diffusion is dependent on sampling time $\left(\mathrm{T}_{\mathrm{S}}=1 \mathrm{hr}\right.$ ) and travel time (t). Source: $\mathrm{S}$. R. Hanna, G. A. Briggs, and R. P. Hosker, Jr. 1982. Handbook on Atmospheric Diffusion, DOE/TIC-11223

(DE82002045), U.S. Department of Energy, National Technical Information Service.

Other diffusion models that have been developed include particle-in-cell, Monte Carlo particle, and Monte Carlo kernel models. Particle-in-cell models (Lange 1978) use inert "tracer" particles that are transported and diffused by the mean wind and turbulent eddies, respectively. These models are fully deterministic (without statistical characteristics that are based on a random component of the wind), and individual particle trajectories that include the interactions between neighboring particles are uniquely calculated. The concentrations are estimated by counting the number of particles in each grid volume. A sufficient number of the particles are "released" so that the counting is representative of expected concentrations.

Monte Carlo particle models calculate the trajectories of large numbers of tracer particles by including random perturbations in the integration of the instantaneous winds over time. The instantaneous wind is assumed to be the sum of the mean wind, a turbulent eddy component correlated with the instantaneous wind at the preceding time step of the model, and a turbulent random (Monte Carlo) component of the wind. The random component is assumed to have a Gaussian distribution. One of the advantages of this model is that diffusion calculations are related directly to basic turbulence characteristics. As in the particle-in-cell model, the concentrations are calculated by counting the number of particles in each grid volume. Because every particle is allowed to move independently from the others, computations for Monte Carlo particle models 
are usually generated more quickly than for particle-in-cell models (in which interactions between neighboring particies are computed).

The Monte Carlo kernel model is similar to the Monte Carlo particle model, with the exception that each particle represents the center of a simulated puff. The concentration distribution within the puff is assumed to be Gaussian, and variances are calculated by integrating with respect to time the velocity variances that occur during the lifetime of the puff. The concentration at a given time and location is estimated as the sum of the concentrations that each puff contributes to that location at that time. No grid volumes are required with this model, and smooth concentration distributions are genirated with a much smaller number of particles than is possible with the Monte Carlo particle model. The Monte Carlo models are most applicable for complicated situations, such as complex topography or land/sea boundaries, in which results from the Gaussian model are suspect.

Because airborne material is removed by deposition processes as it travels downwind, some of the diffusion models include algorithms that account for dry and/or wet deposition (Hanna and Drivas 1987). Material is deposited on vegetation, soil, and water via dry deposition or precipitation scavenging. The latter can be classified as rainout, which is within cloud scavenging, or washout, which is below cloud scavenging, Many physical and chemical factors, such as meteorology, properties of the airborne material, and properties of the receptor surface, influence the deposition of particles and gases (Yamada et al. 1989). Despite detailed theoretical calculations and extensive field and laboratory experiments (Sehmel 1980), much uncertainty remains regarding fundamental parameters. For example, many dry deposition model algorithms have been designed around a single variable, the dry deposition velocity. Because the rates of dry deposition depend on many complex factors, the use of a simple deposition velocity algorithm results in much uncertainty in model predictions.

Because the wind field and diffusion modules must be compatible, the selection of two modules to be coupled is somewhat limited. For example, if a simple Gaussian plume model is desired for the diffusion module, then the coupled wind field usually is constant with time and space; the wind fields predicted by sophisticated prognostic models usually are beyond the capabilities of Gaussian plume models. Similarly, if a constant wind field module is selected, then the advantages of Monte Carlo diffusion models are greatly diminished and a simpler module probably should be chosen. A few exceptions are possible, however, such as models that link spatially and temporally varying winds with Gaussian plume segment diffusion algorithms.

Depending on the application, air dispersion models can calculate concentrations and/or doses expected downwind of an accidental release. Maximum predicted concentrations may be of more value for some types of chemical agents, while dose may be more important for other agents. As mentioned previously, dose is defined as the integration of agent concentration over the duration of exposure (effectively, the multiplicative product of average concentration and time of exposure). Dose at a given downwind location is computed in the models as the summation of concentrations occurring at that location over discrete time intervals. 


\subsection{CRITERIA FOR SELECTION OF AN AIR DISPERSION MODEL}

The choice of an appropriate air dispersion model is crucial to successful emergency preparedness and response. If the selected model is not capable of providing reasonably accurate, timely results to assist the decision-makers, then the consequences from a potential accident could be catastrophic. This section discusses important criteria that should be included in the selection process. These criteria, in relative order of importance (most important first), are listed below. Obviously, the ranking is subjective, but it is included to give a sense of the criticality associated with each criterion.

\section{Accuracy \\ 2. Timeliness}

3. User friendliness

4. Capability of being integrated as part of an automated accident assessment and warning system

5. Ability to estimate the amount of chemical agent emitted into the air

6. Ability to include the effects of local geographical features

7. Ability to integrate real-time meteorological data from multiple meteorological stations

8. Ability to utilize real-time data from a Doppler acoustic sounder

9. Ability to "back-calculate" the quantity at the source from ambient concentrations

10. Limited computer resource requirements

11. Ability to automatically record computer runs in a $\log$

It should be noted that the ranking of criteria for selection of an air dispersion model would vary depending on whether the application is for emergency planning or response. For example, model run time is very critical for emergency response, but not emergency planning. Conceivably, a separate set of criteria could be developed for the two applications that would result in the selection of different air dispersion models for each application. Because the purpose of emergency planning is to prepare for emergency response in the event of an accidental release, however, the latter takes precedence and will be considered above the former in the event of conflicting priorities.

The two most vital criteria in selecting an air dispersion model for emergency response are accuracy and timeliness. These criteria often eontend with each other 
because increased accuracy usually requires corresponding increased computational time on the system computer. For example, reducing the grid spacing in a model will improve results but also increase the execution time. Given this limitation, the two criteria are discussed below.

Of primary importance is that the model should be capable of predicting "accurately" the magnitude and trajectory of a puff or plume. Accuracy is open to subjectivity, but for the purposes of emergency response the model should be accurate enough to predict the dimensions and path of the puff or plume so that appropriate decisions can be made such as the necessity for and geographical extent of protective action. Clearly, a prediction in which the downwind direction is in error by 90 degrees of the compass would be regarded as inaccurate, while a prediction in error by 10 degrees would be considered accurate. Similarly, an estimate of the concentrations or doses at a downwind location would be judged as inaccurate if off by two orders of magnitude but accurate if within $20 \%$. Errors between these extremes are not so easy to judge and will in part depend on a specific accidental release.

The other critical criterion for selection of an emergency response model is the time required to execute or run the model. In an emergency situation, it is vital to obtain results quickly so that decisions can be made regarding response to an accident.

Otherwise, results from the model may not be obtained in time to influence crucial decisions. As noted earlier, the maximum allowable time span after an accidental release to make initial decisions is between 5 and $10 \mathrm{~min}$. Model runs should be made frequently on a routine basis for a variety of scenarios so that preliminary decisions can be initiated immediately after an accident rather than waiting for completion of a model run; in addition, refinements of the model runs probably will be required after the onset of the accident based on the exact nature of the accident and real-time meteorological conditions.

The model should have the capability of being integrated into an automated accident assessment and warning system for making decisions and responding to an accidental release. Otherwise, the usefulness of the model is limited because of the additional time and effort required to interpret the results of the model. In an emergency situation, personnel tend to make mistakes more readily; therefore, an integrated, automated system that allows minimal opportunity for human error is desirable.

The model should be able to integrate real-time meteorological data from multiple meteorological stations. Real-time data from several locations are extremely important in estimating current meteorological conditions such as the wind field. Winds are particularly difficult to estimate because they can vary greatly with time, location, and height. Therefore, the model must be able to accept and integrate data from multiple stations and heights.

To estimate the height of the atmosphere's mixed layer, the model should be able to readily incorporate real-time data obtained by remote sensing from an acoustic sounder. The height of the mixed layer identifies the interlace between the well-mixed layer extending from the surface and the stable layer above (also called the inversion layer 
because the temperature increases with height, rather than decreases with height as occurs usually). This inversion layer forms a lid that essentially prevents chemical agent from spreading upward beyond the mixed layer. As a result, a shallow mixed layer causes relatively high concentrations and doses at distant locations following a ground. level release because of the confinement of the plume between the surface and inversion layer. Therefore, it is important for the model to be able to use data from an acoustic sounder to estimate the height of the mixed layer.

Doppler acoustic sounders also provide wind direction and speed data at heights ranging from about 50 meters to as much as 1500 meters above ground level (agl), and thus are very useful in obtaining a profile of winds at heights beyond the range of meteorological towers. For potential accidents in which the plume from a release rises substantially above the height of the tallest meteorological tower (e.g., a buoyant plume from an intense fire), the data from a Doppler acoustic sounder should be at least as valuable as surface wind data, and the model should be able to utilize these data in estimating the plume trajectory.

The model should have the capability to estirnate the amount of chemical agent emitted into the air. For some releases, this requirement can be met simply by extracting the needed information from a pre-established database. For example, the amount of airborne agent from a fire involving a 1-ton container of VX should be available immediately from the database. For other scenarios, the model would be required to calculate the amount of agent emitted into the air. A spill involving a known quantity of $\mathrm{GB}$ requires that the model calculate the evaporation rate based on meteorological conditions such as wind speed and air temperature in order to estimate airborne emissions.

For some "subtle" accidental releases detected initially by nearby chernical agent monitors, the quantity of the release may have to be estimated from concentrations detected at the monitors. The model should have the capability to "back-calculate" (compute an approximate quantity at the source based on concentrations at agent monitors) quickly so that concentrations and/or doses further downwind can be estimated. Although the estimate of the amount at the source is very "rough" because of uncertainty in identifying the location of the release and/or the location of the centerline of the puff or plume from the release compared with the position of the monitors (i.e., a monitor may be directly downwind of a release or may be offset from the centerline, and the puff or plume may be rising above the monitors or may be "hugging" the ground), this method of obtaining an estimate may be the best available for some accidental scenarios.

The model should be capable of incorporating the effects of local geographical features such as terrain, vegetation, and land/sea interfaces that complicate calculations of concentrations and/or doses at some of the CSDP sites. These features inlluence the meteorology such as the wind patterns, and thus the direction of transport and dilution of agent in the event of an accidental release. The accuracy of the model is dependent on incorporating the effects of these features at the appropriate installations. 
It is important that the model account for topographic features because they can steer the winds in the lower atmosphere and increase or decrease the diffusion of chemical agent. Terrain often channels low-level winds to flow parallel to the axis of a valley. During stable atmospheric conditions (e.g., a temperature inversion), surrounding mountains can act as a barrier by causing a "damming" effect in which most of the agent near the ground would be diverted at the mountains' base to flow parallel to the base of the mountains rather than being lifted over the mountains. Topogiaphy also often generates diurnal circulations during periods of weak large-scale flow, resulting in flow up a slope during the daytime and down at night.

Atmospheric dispersion rates are also dependent on the size of surface obstacles (i.e., buildings, trees, grasses, etc.). Large objects enhance dispersion and, apart from downwash in their immediate wake, reduce downwind consequences of releases. Forests promote increased mixing above their canopy and reduced mixing near the surface. Vegetation also functions as a receptor to remove chemical agent from the air via deposition and absorption. It is important for the model to account for vegetation and other surface obstacles.

Localized circulations develop at land/sea interfaces and must be accounted for in order to derive realistic estimates of plume or puff behavior. During the daytime, for example, a sea breeze often develops when the surface of the land becomes warmer than that of water and heats the air near the land's surface, which causes the air to rise because it is less dense than the surrounding air. Air above the water moves toward land (the sea breeze) to fill the void left by the rising air. Sometimes a complete circle is formed by the rising air reaching the inversion layer, traveling toward sea, and sinking toward the sea surface. During the nighttime, the opposite circulation can develop (the land breeze) when the land surface becomes cooler than the water surface.

An additional consideration for an elevated plume or puff emitted near a large body of water is shoreline fumigation (Fig. 4). Fumigation results when the elevated emissions are traveling with relatively little dispersion in a well-established flow toward land and encounter a thermal internal boundary layer a short distance inland. The thermal internal boundary layer is a consequence of the temperature differential between relatively warm land and cool water. In addition, the increased roughness of the land surface results in increased mixing within the boundary layer. The limited dispersion of the plume or puff in the stable above-water atmosphere changes drastically upon entering the boundary layer in which mixing is vigorous. Fumigation may occur continuously while this situation exists, resulting in higher ground-level concentrations and doses (Lyons 1975; EPA 1988).

The model also should be user friendly so that trained personnel can run it easily, both on a routine basis and immediately after the onset of an accident. User friendliness is especially important in the event of an accident because personnel are more prone to commit errors during a stressful situation. A menu-driven approach is recommended for the system. Model input should be automated as much as possible so that a minimal amount of user interaction is necessary in the default mode. The model should be llexible enough, however, to allow personnel the option of overriding default parameters. Output 


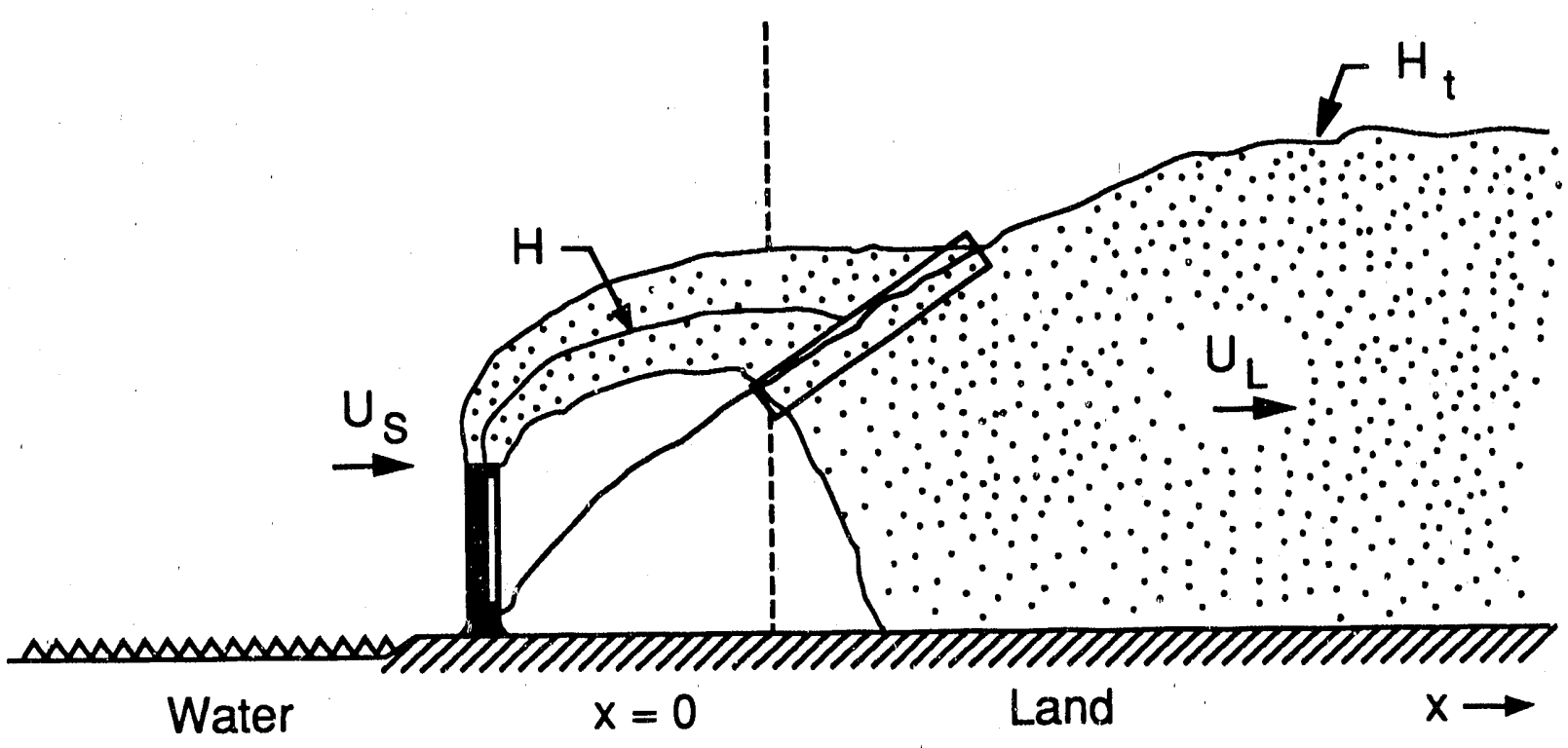

Fig. 4. Illustration of shoreline fumigation. Source: U.S. Environmental Protection Agency 1988. User's Guide to SDM-A Shoreline Dispersion Model, EPA-450/4-88-017, U.S. EPA, Research Triangle Park, N.C.

from the model should be available in understandable graphical form to enhance the interpretation of results. For example, geographical areas with predicted doses greater than critical values can be color coded and superimposed on a map background to indicate the severity and areal extent of an accident. To identify easily the area of concern, the map background should include important geographical features such as the installation boundary, towns, roads, and rivers; the graphics should be capable of being magnified or reduced so that the color-coded dose contours for a given accident cover a large percentage of the map projection but do not extend beyond the edge of the projection.

The model should be able to run on a computer of relatively modest resources. It is unrealistic to expect that a supercomputer will be available at each of the eight sites, but rather a smaller computer dedicated to running the model (probably a microcomputer). Dedication of the machine is important to ensure that it is available when needed. Operation of the model on a microcomputer should not be a serious drawback, except perhaps for the most sophisticated models, because of tremendous advances in storage and speed of the machines over the past several years.

A $\log$ containing details of each of the model runs such as input parameters and results from the runs should be recorded automatically by the model so that personnel have an available record of previous runs, and investigations conducted after an accident would have appropriate documentation regarding the number, type, sequence, and timing of runs. In addition, a log is a useful tool for evaluating the actions of personnel during a drill or an actual accident in order to imprcve future performance and is invaluable for potential litigation resulting from an accident. 


\subsection{MODEL VERIFICATTON}

The model or models selected for use in the emergency response program should be validat $2 d$ at each site to ensure that the modeling results are accurate enough to incor porate into the overall decision-making system at the site. Tracer studies (Draxler 1981; Heiken 1986), in which specified amounts of an easily detectable innocuous substance are released into the atmosphere and ambient levels are measured at various locations downwind, are a necessary part of the validation process. Otherwise, there is no assurance that the selected model is accurately simulating the site-specific characteristics such as topography, vegetation, and land/sea interface. Although tracer studies are timeconsuming and expensive, they are necessary to verify and fine-tune model results. In addition to being easily detectable and harmless, the tracer should be inert, available at relatively low cost, and exist at extremely low background levels in the atmosphere. Sulfur hexafluoride $\left(\mathrm{SF}_{6}\right)$ is one of the most commonly used tracer materials.

Tracer studies have been performed in the atmosphere since 1926 (Heiken 1986). Early experiments were performed to study the role of diffusion in the basic structure and dynamics of the atmosphere. The experiments were designed so that conditions were as uniform as possible (e.g., flat terrain, consistent height of vegetation and other obstacles, and steady meteorological conditions) to minimize other complicating factors. Usually, groups of receptors to sample the tracer material were positioned in arcs oriented perpendicular to the path of the material at varying distarices downwind. Sampling of material at varying heights also was performed in some of the studies to evaluate the effects of diffusion in the vertical direction as well as the horizontal direction. Results from the early tracer studies indicated that a Gaussian distribution often provides a good estimate of dispersion in the cross-wind and vertical directions as material moves downwind. Curves based on a Gaussian distribution have been developed to estimate the cross-wind and vertical spread of material as a function of atmosphciic stability and downwind distance.

Since the passage of the National Environmental Policy Act and Clean Air Act (as amended) in 1969 and 1970, respectively, preparation of environmental impact statements and air permit applications has forced increased emphasis on the characterization of dispersion of emissions from specific sources. Whereas earlier tracer studies were performed to glean additional basic knowledge of diffusion processes, most studies since the 1970s have attempted to characterize atmospheric dispersion at specific locations and as a result have been required to incorporate applicable site-specific factors such as complex topography, urban areas, vegetation, and shorelines. Because of these factors, more sophisticated experiments have been designed and executed that usually require a larger, denser network of receptors for sampling tracer material than the earlier experiments. Results from such experiments provide an accurate portrayal of dispersion processes in the area surrounding a given location.

Tracer studies, therefore, are an important tool for depicting the atmospheric environment around a specific location and provide "ground truth" for validating and finetuning air dispersion models. Careful attention should be given to establishing objectives, designing and executing the experiments, and analyzing and interpreting the data. For the 
CSDP, it is important to verify at each of the eight sites the results of the model or models selected for use in the emergency response program, including the currently used D2PC model (Whitacre et al. 1987) if it is chosen. 


\section{MONITORING REQUIREMENTS}

\subsection{METEOROLOGICAL MONITORING}

The design and implementation of an appropriate meteorological monitoring network is vital to the success of the emergency response program. Without a well-chosen and implemented system, the probability of a successful response is substantially diminished. The most obvious example of necessary meteorological instrumentation is a single wind vane positioned appropriately to estimate the direction of the downwind area potentially impacted by an accidental release. Much additional monitoring equipment is required, however, to effectively respond to a release. The monitoring must be integrated with air dispersion modeling to generate results useful to decision-makers.

The following meteorological parameters should be monitored continuously at meteorological stations as part of a comprehensive program: wind speed, wind direction, air temperature, and height of the mixed layer. Meteorological towers should be instrumented with sensors to measure temperature and wind speed and direction at three levels: near the ground, at about $10 \mathrm{~m}$ agl, and at approximately the level of the disposal facility stack (estimated to be about $38 \mathrm{~m} \mathrm{agl}$ ). A Doppler acoustic sounder should be installed to obtain the height of the mixed layer and a profile of wind direction and speed at heights ranging from about 50 meters to as much as 1500 meters agl. The coupling of data from meteorological towers and a Doppler acoustic sounder ensures that the entire vertical range of winds is characterized for that portion of the atmosphere in which the plume from an accidental release may travel.

As mentioned previously, measurements of wind direction are critical for delineating the area downwind of a release. Wind speed is also very important because it determines the time that a release takes to reach a given downwind distance, and it affects the dose resulting from a release. Wind speed and air temperature are factors in the rate of volatilization of chemical agent following a spill. The height of the mixed layer forms an upper limit of dispersion of material in the atmosphere; dispersion above this height into an inversion layer occurs at a greatly reduced rate. Ground-level concentrations and doses become affected by this height at greater downwind distances in which the vertical distribution of agent becomes uniform between the ground and the height of the mixed layer. Therefore, for plumes that remain near the ground, the lower the height of the mixed layer, the greater the concentrations and doses at large downwind distances. For elevaled plumes, an inversion near or on the ground results in low concentrations and doses if the plume is above the inversion because downward diffusion of material through the inversion layer is extremely limited.

It is also vital to estimate atmospheric stability (a measure of the atmosphere's tendency to either resist or enhance turbulent motions) from the above parameters because consequences of releases are highly dependent on stability. Downwind groundlevel concentrations and doses resulting from ground-level releases are smaller, in 
general, for unstable atmospheric conditions than stable conditions. Two methods should be used to estimate atmospheric stability. The first method involves computing the standard deviation of the horizontal wind direction. The computation should be derived from measurements taken at the level nearest the centerline of the release after allowing for any plume rise resulting from buoyancy or initial momentum of the release. Large standard deviations are indicative of large fluctuations in wind direction that, in turn, reflect unstable atmospheric conditions; conversely, small standard deviations are indicative of stable conditions. This method works especially well for determining atmospheric mixing in the horizontal direction.

The second method for calculating atmospheric stability examines the change of air temperature with height. Atmospheric stability is strongly, though not solely, dependent on the change of temperature with height in the atmosphere. The more rapidly the temperature decreases with height, the less stable the atmosphere is, allowing greater mixing and enhancing dispersion so that ground-level concentrations and doses resulting from ground-level releases would be reduced. A large decrease in temperature with increasing height denotes an unstable atmosphere, whereas no change or an increase in temperature with height denotes a stable atmosphere. To obtain the change of temperature with change in height, the computation should be derived from measurements taken at two levels: $10 \mathrm{~m}$ agl and at the level of the disposal facility stack. This method works particularly well for determining atmospheric mixing in the vertical direction.

The instrumentation network should include at least two properly sited meteorological towers at each of the installations. This minimum number provides assurance that instrumentation on one tower will be operating if equipment on the other tower fails or is providing erroneous data. Two towers permit quality assurance checks for proper equipment performance and calibration. More than two towers are required at most sites including some towers located beyond installation boundaries, if possible, because of localized circulations that develop at sites with complex terrain or a nearby water body; some sites may need as many as ten towers. Multiple meteorological towers are especially important to provide input to an air dispersion model that is capable of developing a wind field corresponding to the time of observation and/or forecasting future wind fields. A single Doppler acoustic sounder at each installation is sufficient because of the cost of the instrumentation and the relative uniformity in the horizontal direction of the height of the mixed layer and the winds aloft.

It is important to note that the instrumentation would serve other functions within the CSDP beyond the immediate scope of the emergency response program, such as providing input for a continuous assessment of incident-free operations of the disposal facility. Data from the meteorological towers, which should be operational at least 2 years before operation of the facility, would initially be used to site instrumentation that would measure air pollutants regulated by the Clean Air Act and chemical agents for long-term comparisons with background concentrations. The locations of agent and pollutant monitors should be based partially on modeling studies using the first year of site-specific meteorological data. One year of pre-operational data from the monitors, coupled with meteorological data from the towers for that year, would provide a baseline 
to compare with data collected during facility operation. The Doppler acoustic sounder should also be operated for 1 year before facility operation to obtain background measurements and familiarity with the equipment. At some installations, the role of the meteorological instrumentation may be expanded to include operations outside the scope of the CSDP that also require an emergency response capability. A meteorological network of this sophistication should be able to serve a multiple purpose if the need exists.

Data from the meteorological network should be available in real-time via telemetry from the instrumentation to a central receiving and processing facility on the installations (e.g., the Emergency Operations Center). The central facility should be sited in a location that is at a sufficient distance from the disposal facility and storage areas to preclude the possibility of evacuation resulting from a potential fire or explosion at the latter areas. Processed data should be recorded in a format that is accessible as input for automatic execution of an air dispersion model and available for immediate examination and analysis by the staff. Software programs should be developed that display the data graphically on computer terminal screens for easy viewing and interpretation. The graphical depiction of wind vectors (wind direction and speed) is of primary importance for obtaining a better unders ${ }^{\star}$ anding of the wind field (the characteristics of the wind throughout an area rather than at a single location) and changes of wind with height and time. Drawings of wind trajectories (the path of a puff of air with time) should be included as one of the graphical displays. Similar displays of the other meteorological parameters, although not as critical, would be very useful.

Backup power (e.g., a diesel generator and/or batteries) should be available immediately to the integrated system in the event that normal electrical service is disrupted. The cause of an accidental release also may interrupt electrical service; therefore, provisions should be made to enable the system to operate in the absence of the usual source of electricity.

Finaily, it is important to keep the meteorological monitoring network maintained properly. Regular maintenance is needed to inspect and calibrate the equipment to ensure instrument reliability and data accuracy. The interval between calibrations should not exceed 1 year. Periodic quality assurance checks of data should be performed by trained personnel.

A suggested enhancement in parallel with meteorological monitoring at the installations is the capability of accessing current meteorological observations, analyses, and forecasts from the NWS, either directly via the AFOS network, if feasible, or indirectly through a private service. This data link would provide meteorological dat" that are beyond the geographical range of the CSDP monitoring network which are extremely useful in forecasting future weather conditions that could have a substantial impact on decision-making, such as wind shifts due to approaching fronts. In addition, the data link provides important products to assist in emergency planning and response, such as analyses of synoptic-scale data and numerical and statistical weather forecasts. 


\subsection{AGENT MONITORING}

In the event of an accidental release of chemical agent, major concerns include detection and characterization of the release (c.g., type of agent, quantity of agent, and type of release). An integrated accident assessment and warning system must include the capability to detect and characterize a release as soon as possible and to provide an early warning, if necessary, of potential danger to the general public. Agent monitoring is an important component of the integrated system. Although the details of agent monitoring are beyond the scope of this document, some general observations are noted because of the interconnection between agent monitoring and atmospheric dispersion modeling and meteorological monitoring.

An important function of agent monitoring is to provide an early warning that an accidental release has occurred. While some modes of release are immediately apparent by sight and sound (e.g., detonation of a munition containing chemical agent). other relcases may be much more subtle and escape quick detection (c.g., a leaking munition). Agent monitoring is necessary to ensure that a release is detected as soon as possible before any potential harm occurs to the general public. To achieve this objective, monitors should be located as close as possible to potential sources; the positioning of monitors near the sources also minimizes the possibility of a release escaping detection. Specifically, monitors should be located inside the disposal facility and in the stack exhaust ducts to warn of a release during operation of the facility. Monitors should also be placed within the chemical storage yard and along its perimeter. During transport of the chemical munitions from a storage igloo to the facility, additional agent monitors should be positioned in the vicinity of the igloo and along the path of transport.

In addition to detecting an accidental release, the release must be characterized so that appropriate actions can be taken by decision-makers. Although certain actions may be obvious for some releases (e.g., the release is large enough that it is realized immediately that protective action by the general public is required), other releases may require estimates of their magnitude before decisions can be made. While the sizes of some potential accidents are obvious without monitoring (e.g., a ton container containing chemical agent that ruptures during handling) and can be estimated easily without monitoring, there are other scenarios for which monitoring will play a key role in estimating the size of a release. Although monitoring will provide only a rough estimate rather than an exact amount because of uncertanty in identifying (1) the location of the release and/or (2) the location of the centerline of the puff or plume from the release compared with the position of the monitors, an estimate is needed as input for the air dispersion model. The model, in turn, should have the capability to "back-calculate" the quantity at the source, given the concentrations at the monitors, so that concentrations and/or doses further downwind can be calculated. Monitoring will also identify the type of agent(s) in the release. Information from the monitors should be available in realtim. via telemetry to the central receiving and processing facility on the installations. 


\section{PERSONNEL REQUIREMEINTS}

Well-trained personnel are an integral part of emergency response. Integrated, highquality modeling and monitoring capabilities need to be coupled with well-trained personnel that can respond in the event of an accident. At least two people with an educational background in meteorology (or a closely related field) should be stationed at each of the CSDP installations to interpret the results properly. Decision-making without the assistance of a trained meteorologist would lower considerably the probability of successful emergency response to an accident.

The following actual incident is provided as an illustration to support the argument for the presence of meteorologists at the installations. At one of the CSDP installations in which no meteorologists currently are stationed, the wind direction measured at the nearest windset is displayed in real-time in the Emergency Operations Center. Unfortunately, a few years ago the windset was miscalibrated so that the indicated wind direction was 180 degrees from the true direction. In the event of an accident, this error would have caused confusion at the very least and possibly could have resulted in disaster by evacuating people into a downwind plume rather than upwind away from the area of danger. To prevent this type of situation, a trained meteorologist would ensure that instrument calibration is performed correctly at regular intervals and would be able to detect problems before they become potential catastrophes. A trained professional is not as likely to take instrument readings and model results at face value but rather is able to determine the reasonableness of data and correctly interpret model results to provide needed guidance in the event of an accident.

Although several techniques can be applied to simplify the results of the integrated modeling and monitoring system so that interpretation is not so complicated (e.g., the multitude of scenarios predicted by the system associated with many types of potential releases and meteorological conditions may be categorized into several groups with corresponding plans of action), a trained meteorologist would still be required to provide subjective judgment for decision-making involving scenarios that are not clear-cut. Certainly a major release requiring protective action by many people will require the input of a trained professional.

If the disposal facilities at the installations operate $24 \mathrm{hr}$ per day, it is logical to ask if meteorologists are needed on duty around the clock. If the personnel and financial resources are available, continuous meteorological support is definitely desirable. Realistically, however, the probability of stafling five meteorologists (the number required to maintain operations around the clock allowing for sick leave and vacation) at eight installations is low. These professionals would be required not only to work rotating shifts but also to spend much of their time on fairly mundane tasks because their primary function would be to assess the potential hazard from an accidental release and provide input to decision-makers. Some of the boredom would be relieved by responsibilities associated with normal operation of the disposal facilities, especially if operations are dependerit on favorable meteorological conditions such as the absence of 
thunderstorms in the area. Weather forecasting for disposal operations and overall installation activities should spark additional interest in the positions. Nevertheless, an intensive effort would be required to keep the work stimulating so that the positions would remain filled and the meteorologists would be prepared in the event of an accident.

As an alternative to maintaining around the clock meteorological support, it is suggested that each installation have two metcorologists. They can work overlapping shilits (e.g., 7:00) a.m.-3:30 p.m. and 2:00 p.m.-10:30 p.m.) to cover a near-maximum period of time and yet have a small amount of time to exchange information. Note that if the disposal facility is operating around the clock, then the midnight shift may be one of the rcquired shilts because the potential consequences for a given accident usually are greatest between midnight and sunrise (the atmosphere is most stable during this period). An important function of the meteorologists would be to train other personnel involved in emergency response so that, if the meteorologists are not on duty in the event of an accident, preliminary decisions can be made before they arrive on the installation. Both meteorologists would be required to carry "beepers" so that they could be notified immediately of an accident. It is vital for two meteorologists to be stationed at the installation to ensure that one is always readily availat)le (i.e., to allow for sick leave, vacations, transfer, etc.).

Continuous training activities conducted by the metcorologists would serve several functions. Not only would the training increase the aptitude of emergency response personnel, but the activities also would stimulate the meteorologists and minimize boredom. The constant interaction among personnel should promote a sense of teamwork. In addition, the meteorologists would have the responsibilities associated with normal operations that have been mentioned previously. 


\section{SITE-SPECIFIC REQUIREMEN'IS AND CAPABILITIES}

Requirements of air dispersion modeling and meteorological monitoring as part of an integrated accident assessment and warning system are generally similar at each of the eight CSDP installations. Important differences in geography, however, affect the meteorology and result in additional requirements at some of the sites. Topographical influences play an important role at TEAD, UMDA, and ANAD. Diurnal circulations generated by topography during periods of weak large-scale llow that result in up-valloy flow during the daytime and down-valley flow at night are especially pronounced at TEAD. PBA and ANAD are in heavily wooded terrain that influences the dispersion characteristics of the locale. Land/sea breezes often develop at APG because it is situated along the shore of the Chesapeake Bay. Table 1 lists the local geographical features and their effects on meteorology at the installations. These factors must be considered in the tailoring of air dispersion models to ensure that their eflects are incorporated.

Similarly, the meteorological monitoring network must be configured to measure local atmospheric conditions adequately and rellect the effects of geographical influences. A denser network of instrumentation is necessary at installations with pronounced geographical features (i.e., lopography, woods, or large water bodies) because of the localized flow patterns that develop. For example, the number of necessary meteorological towers may increase from the minimum of two towers to as many as ten towers.

In addition to geographical features that alfect local meteorology, the distribution of population around the installations may influence the requirements for site-specilic modeling and monitoring. For example, as depicted in Table 2, the distance from the installation to the nearest resident varies from less than $1 \mathrm{~km}$ at NAAP to greater than $2 \mathrm{~km}$ at APG, ANAD, PBA, and TEAD. This variation in distance translates into a site-specific variation in time available to warn the nearest resident of an accidental release and may affect the selection of an air dispersion model or operational procedures for running a model at a site. Similarly, Table 2 indicates a large variation in the number and distribution of residents within $100 \mathrm{~km}$ of the installations. At installations such as APG, ANAD, LBAD, and PBA that are within $20 \mathrm{~km}$ of a great number of residents, varying models, monitoring networks, and operational procedures may be required to ensure adequate time for protective action such as evacuation. Specifically, depending on other factors such as quantity and quality of evacuation routes, a greater lead time may be needed to evacuate successfully at these sites. Because population size within $20 \mathrm{~km}$ of NAAP, PUDA, TEAD, and UMDA is smaller, the requirements of modeling and monitoring as tools in the decision-making process for protective action may be less stringent at these sites.

Requirements for acquisition of hardware such as meteorological towers, meteorological instrumentation, data telemetry, and computer work stations may vary among installations depending on the availability of existing good-quality hardware that 


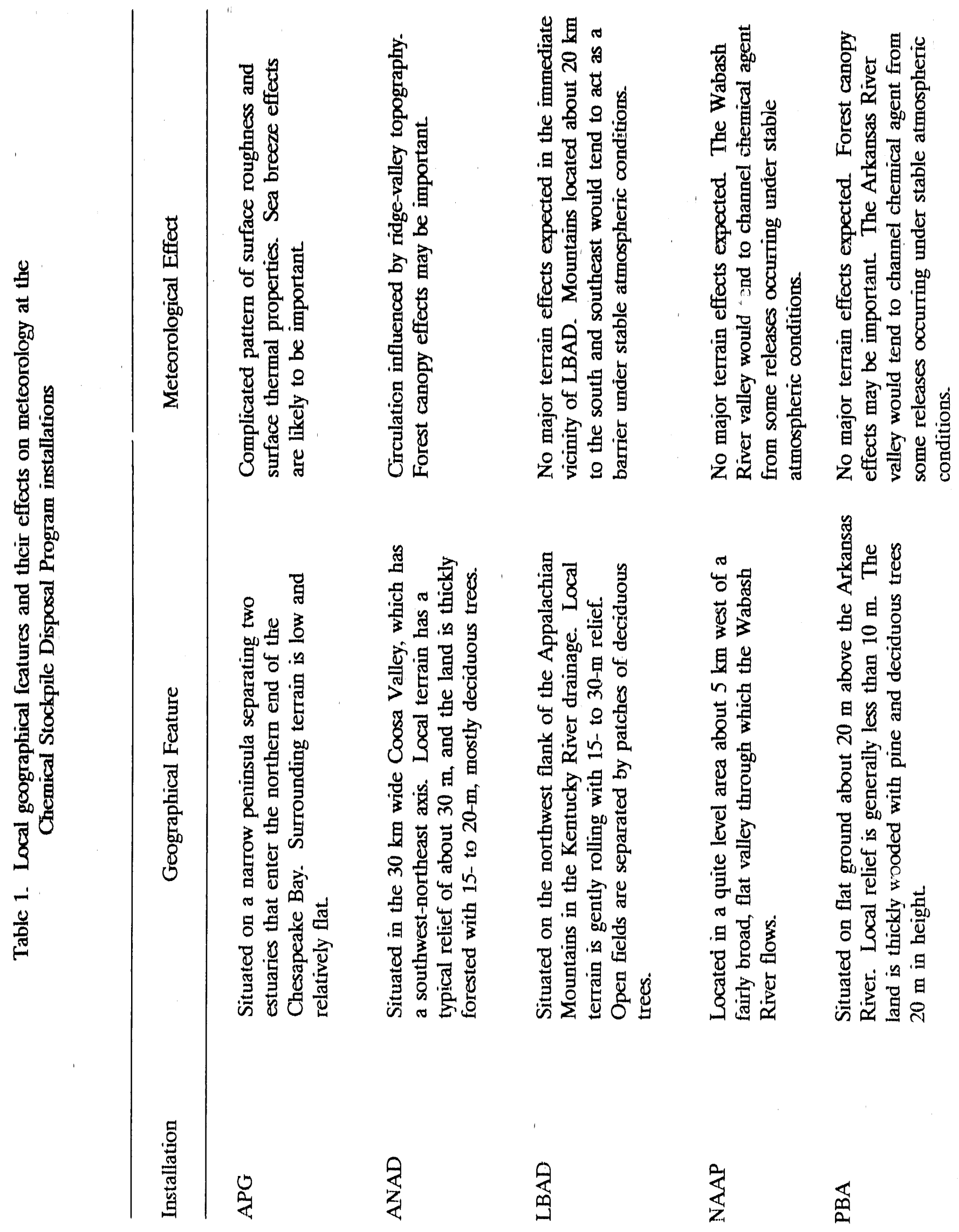




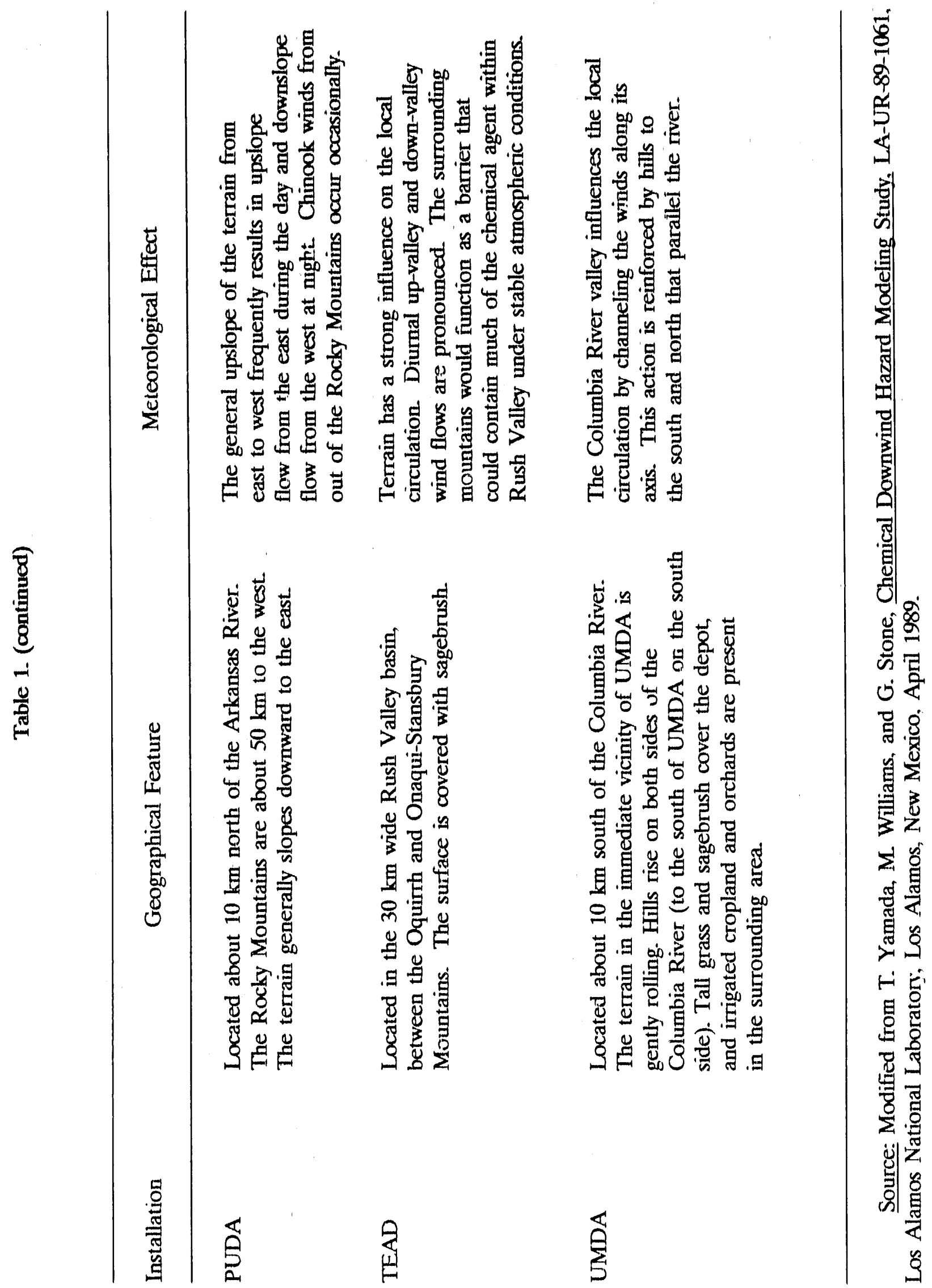


Table 2. Estimeted Population Around tho Chemical Stockpilc Disposal Program Installations

\begin{tabular}{|c|c|c|c|c|c|c|c|c|}
\hline \multirow[b]{2}{*}{ Installation } & \multicolumn{8}{|c|}{ Incremental population at specified distances $(\mathrm{km})$} \\
\hline & $0-1$ & 1.2 & $2-5$ & $5-10$ & $10-20$ & $20-35$ & $35-50$ & $50-100$ \\
\hline $\mathrm{APG}^{\prime}$ & 0 & 0 & 13,092 & 30,962 & 159,807 & 930,177 & $N A^{b}$ & $\mathrm{NA}$ \\
\hline ANAD" & 0 & 0 & 1,771 & 20,478 & 81,361 & $93,(007$ & 123,933 & $1,233,892$ \\
\hline $\mathrm{LBAD}^{\prime \prime}$ & 0 & 20 & 1,637 & 25,192 & 30,268 & 72,852 & NA & NA \\
\hline NAAPc $^{c}$ & 43 & 118 & 774 & 3,564 & 16,511 & 80,862 & 196,387 & 836,055 \\
\hline $\mathrm{PBA}^{\prime \prime}$ & 0 & 0 & 1,090 & 5,494 & 66,977 & 39,092 & 211,282 & $497,(080$ \\
\hline $\mathrm{PUDA}^{\mathrm{c}}$ & 0 & 6 & 62 & 346 & 5,246 & 110,574 & 11,921 & 366,382 \\
\hline TEAD" & 0 & 0 & 2 & 99 & 967 & 22,910 & 152,737 & $1,001,652$ \\
\hline $\mathrm{UMDA}^{\mathrm{c}}$ & 0 & 10 & 295 & 3,730 & 20,236 & 4,599 & NA & NA \\
\hline
\end{tabular}

"Estimated 1986 population.

"NA = not available.

'1980 data.

Source: S. A. Carnos, Site-Specific Emergency Response Concept Plans for the Chemical Stockpile Disposal Progrum: A Comparative Summary, ORNL/TM-11357, Oak Ridge National Laboratory, Oak Ridge. Tenn., December 1989.

can be applied in the CSDP. Although it is not expected that a lirge amount of current equipment will mret the requirements, some meteorological towers (e.g., at APG, ANA.), PBA, arıd TIEAD) may suffice. If existing hardware is questionable for use with the CSDP, however, then new hardware should be acquired; although new equipment will be more expensive, it will ensure maximum proficiency and flexibility.

Existing air dispersion modeling and meteorological monitoring capabilities and training of personnel in these activities vary considerably at the installations. The D2PC model (Whitacre et al. 1987) is used at all the sites but has been modified at some of the installations: at ANAD, for example, the user-interaction portion of the model has been changed, and graphics superimposed on a map background are included as part of the output. An air dispersion model named MACH 1-3D (Real-time Army Model of Atmospheric Chemical Hazards) developed by Ronald E. Meyers of the U.S. Army Atmospheric Sciences Laboratory at White Sands Missile Range, New Mexico, has been tested at PBA but was found to need major improvements before it would be useful. Much development and testing has been undertaken at TEAD for the HOTMAC and RAPTAD model developed by Los Alamos National Laboratory (Yamada et al. 1989). 
Tracer studies performed at TEAD indicated that the model could simulate atmospheric transport and dispersion processes quite well. Currently, neither the MACH 1-3D nor HOTMAC and RAPTAD models are running operationally at any of the installations.

Some of the installations such as APG, ANAD, PBA, and TEAD have sophisticated instrumentation at multiple meteorological towers; as discussed above, it should be possible to incorporate the instrumentation into an integrated accident assessment and warning system. Data from the meteorological instrumentation at these sites are automatically transmitted by telemetry, recorded at the Emergency Operations Center, and available for access by the D2PC model. Other installations such as NAAP and UMDA have a minimal amount of antiquated equipment that is inadequate for use in an integrated system and thus require a completely new system. Data at these sites are not automatically available for the D2PC model but must be estimated manually from dials or strip charts. Table 3 lists the current meteorological monitoring and air dispersion modeling capabilities at the installations.

The level of training and number of personnel trained in air dispersion modeling and/or meteorological monitoring vary substantially among the installations. Most sites have employees that are able to run the existing air dispersion model but lack a formal educational background in atmospheric science. An exception to this rule occurs at TEAD, where six members of the U.S. Army Atmospheric Sciences Laboratory are stationed, and at PBA, where a meteorologist works under contract. Employees without a formal background have been able to educate themselves quite well at some sites, while at other sites the employees treat the air dispersion model as a "black box." 


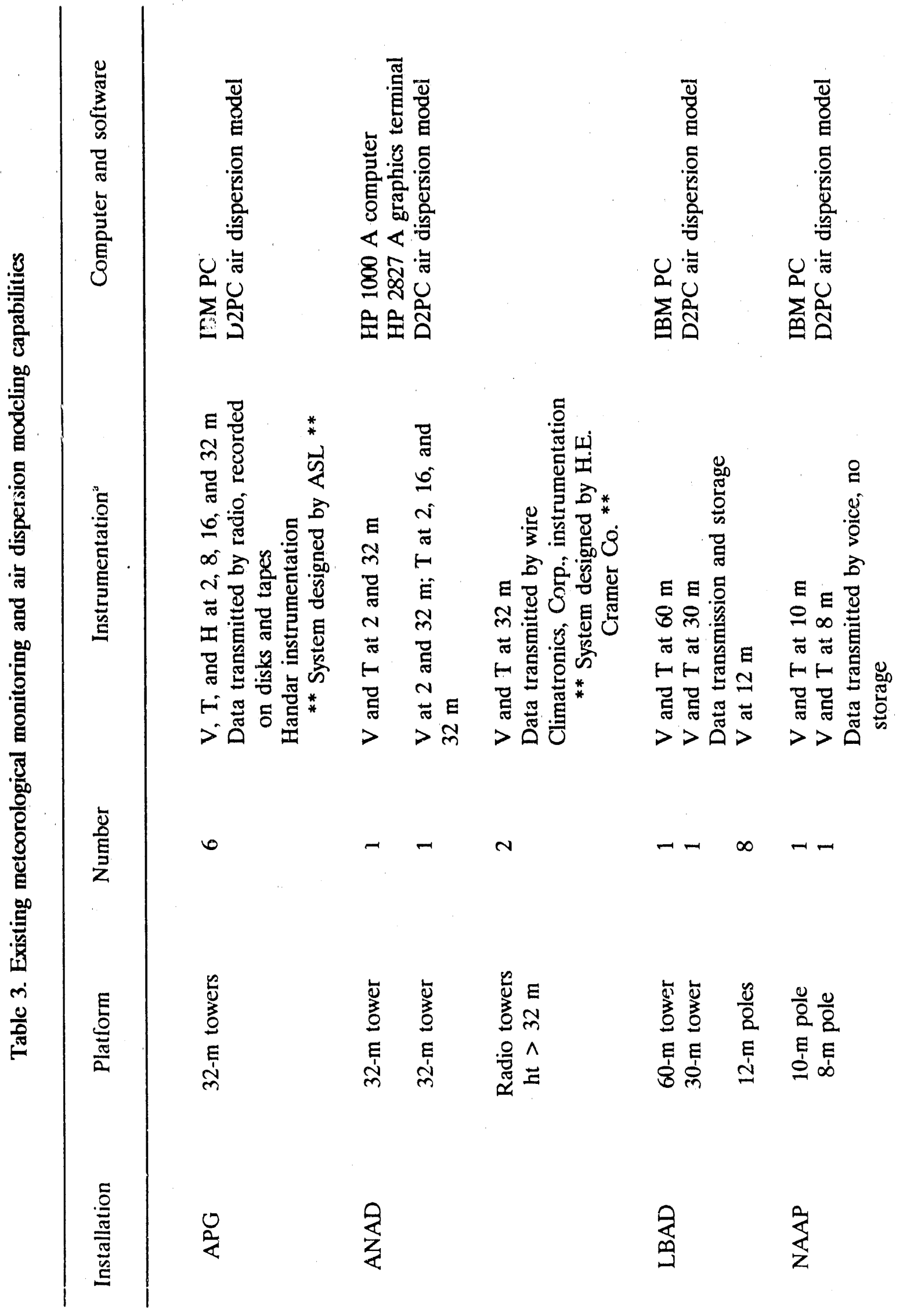




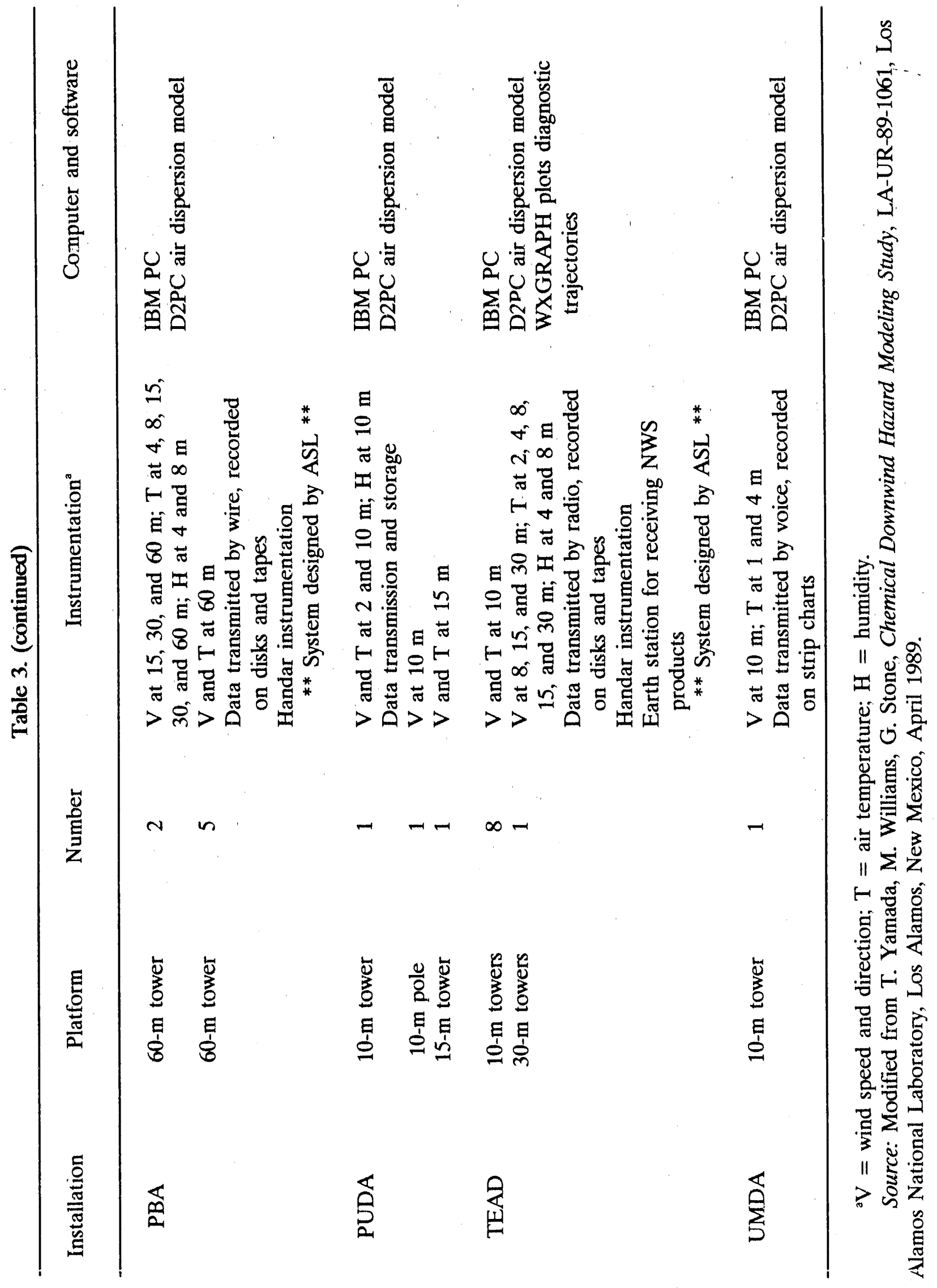




\section{SUMMARY AND RECOMMENDATIONS}

As one of the CSDP technical support studies completed for emergency planning, this report examined the purpose of and developed requirements for atmospheric dispersion modeling and meteorological monitoring in support of an integrated accident assessment and warning system. A review was performed to assess the capabilities of operating state-of-the-art systems and define a baseline for developing the requirements of the CSDP system. Atmospheric dispersion modeling and meteorological monitoring form vital components of current systems. Air dispersion models calculate concentrations and/or doses expected downwind of an accidental release to predict poteritial consequences from an accident prior to the arrival of chemical agent downwind. The models generally consist of two components or modules: the first module determines the wind field, and the second module calculates the diffusion of agent. Meteorological monitoring is performed to characterize the atmospheric environment into which an accidental release would be emitted.

The selection of an appropriate air dispersion model is crucial to the success of the CSDP emergency response program. A review was conducted of the types of models currently available. The two most important criteria in choosing a model are accuracy and timeliness. The model should be capable of predicting "accurately" the magnitude and trajectory of a puff or plume from a given release. For the purposes of emergency response, the model should be accurate enough to predict the dimensions and path of the puff or plume so that appropriate decisions can be made such as the necessity for and geographical extent of protective action. Execution time for running the model should be short to obtain results quickly so that decisions can be made regarding response to an accident. Because the maximum allowable time span after an accidental release to make initial decisions is between 5 and $10 \mathrm{~min}$, model runs should be made continuously on a routine basis for a variety of scenarios so that preliminary decisions can be initiated immediately after an accident rather than waiting for completion of a model run; refinements of the model runs will be needed after the onset of the accident based on the exact nature of the accident and real-time meteorological conditions. One possibility for model selection that should be investigated is the choice of two models: a sophisticated prognostic model requiring a moderate amount of execution time and a very simple model that runs almost instantly. The former model would be run routinely so that, in the event of an accident, "accurate" results that are not too outdated would be available immediately; the latter model would be run immediately following an accident to obtain a first look at potential consequences for the given accident while waiting for fresh results from the sophisticated model.

An essential criterion is that the model(s) should be user friendly so that trained personnel can run it easily, both on a routine basis and immediately after the onset of an accident. User friendliness is especially important in the event of an accident because personnel are more prone to commit errors during a stressful situation. A menu-driven approach is recommended for the system. Model input should be automated as much as possible so that a minimal amount of user interaction is necessary 
in the default mode. The model should be flexible enough, however, to allow personnel the option of overriding default parameters. Output from the model should be available in understandable graphical form to enhance the interpretation of results.

Other criteria also are important in the selection of an air dispersion model. The model should have the capability of being integrated as part of a comprehensive accident assessment and warning system for making decisions and responding to an accidental release. The model should be able to run on a computer of relatively modest resources, most likely a microcomputer. Dedication of the machine is important to guarantee that it is available when needed. The model should also be able to integrate real-time meteorological data from multiple meteorological stations. The model must be able to accept data from multiple stations and heights and integrate the data to obtain a more complete picture of the current meteorological conditions than is possible with a single station. The model also should be able to readily utilize data from Doppler acoustic sounders to obtain a reasonable estimate of the height of the atmosphere's mixed layer and the winds aloft. In addition, the model should have the capability to estimate the amount of chemical agent emitted into the air. For some releases, this requirement can be met simply by extracting the needed information from a pre-established database; for other scenarios, the model would be required to calculate the amount of agent emitted into the air (e.g., from a spill). For accidental releases in which the quantity emitted has to be estimated from concentrations detected at nearby chemical agent monitors, the model should have the capability to "back-calculate" so that concentrations and/or doses further downwind can be estimated. The model should be capable of incorporating the effects of local geographical features such as terrain, vegetation, and land/sea interfaces that complicate calculations of concentrations and/or doses at some of the CSDP sites. A log containing details of each of the model runs should be recorded automatically by the model so that personnel have an available record of previous runs and investigations conducted after an accident would have appropriate documentation regarding the runs.

The design and implementation of an appropriate meteorological monitoring network are vital to the success of the emergency response program. Monitoring must be integrated with air dispersion modeling in order to generate results useful to decisionmakers. If the need exists, the instrumentation should be able to serve other functions within the CSDP beyond the immediate scope of the emergency response program, such as providing input for a continuous assessment of incident-free operations of the disposal facility. Data from the meteorological network should be available in real-time via telemetry from the instrumentation to a central receiving and processing facility on the installations.

The following meteorological parameters should be monitored continuously at meteorological towers as part of a comprehensive program: wind speed, wind direction, air temperature, and height of the mixed layer. The towers should be instrumented with sensors to measure temperature and wind speed and direction at three levels: near the ground, at about $10 \mathrm{~m} \mathrm{agl}$, and at approximately the level of the disposal facility stack. Atmospheric stability should be estimated from measurements of wind direction and temperature. A Doppler acoustic sounder should be installed to obtain the height of the mixed layer and a prolile of the winds aloft. 
The instrumentation network should include at least two properly sited meteorological towers at each of the installations. This minimum number provides assurance that instrumentation on one tower will be operating if equipment on the other tower fails or is providing erroneous data. More than two towers are required in most locations because of localized circulations that develop at sites with complex terrain or a nearby water body, and some sites may need as many as ten towers.

A review of present air dispersion modeling and meteorological monitoring in support of emergency response at the eight U.S. Army chemical stockpile depots involved in the CSDP revealed that existing modeling and monitoring capabilities vary substantially at the installations. The D2PC model is utilized at all of the sites but has been modified at some of the installations. Some of the installations such as APG, ANAD, PBA, and TEAD have sophisticated instrumentation at multiple meteorological towers, while others like NAAP and UMDA have a minimal amount of antiquated equipment that is inadequate for use in the CSDP. Data from the meteorological instrumentation at the former sites are automatically transmitted by telemetry, recorded at the Emergency Operations Center, and available for access by the D2PC model, while data at the latter sites are not automatically available for the D2PC model but must be estimated manually from dials or strip charts.

Differences among installations in requirements for air dispersion modeling and meteorological monitoring are relatively small compared with the magnitude of the accident assessment and warning system that is needed. Important differences in geography, however, affect the meteorology and result in additional requirements at some of the sites. For example, topographical influences play an important role at TEAD, UMDA, and ANAD. PBA and ANAD are in wooded terrain that influences the dispersion characteristics of the locale. Land/sea breezes often develop at APG because it is situated along the shore of the Chesapeake Bay. In addition to geographical features that affect local meteorology, the distribution of population around the installations may influence the requirements for modeling and monitoring; and requirements for hardware acquisition such as meteorological towers, meteorological instrumentation, data telemetry, and computer work stations may vary among installations depending on the availability of existing acceptable hardware that can be used in the CSDP. These factors must be considered in the design and implementation of modeling and monitoring at each of the installations.

In addition to air dispersion modeling and meteorological monitoring, well-trained personnel are an integral part of emergency response. At least two people with an educational background in meteorology (or a closely related field) should be stationed at each of the installations to interpret the results properly, ensuring that one is always readily available (i.e., to allow for sick leave, vacations, transfer, etc.). The meteorologists can work overlapping shifts to cover a near-maximum period of time and yet have a small amount of time to exchange information. An important function of the meteorologists would be to train other personnel involved in emergency response so that, if the meteorologists are not on duty in the event of an accident, preliminary decisions can be made before they arrive on the installation. Both meteorologists would be required to carry "beepers" so that they could be notilied immediately of an accident. 
Decision-making without the assistance of a trained meteorologist would lower considerably the probability of successful emergency response to an accident.

The level of training and number of personnel trained in air dispersion modeling and/or meteorological monitoring vary substantially among the installations. With the exception of TEAD and PBA, CSDP sites lack employees that have a formal educational background in atmospheric science. Employees without such a background have been able to educate themselves quite well at some sites, while at other sites the employees treat the air dispersion model as a "black box." During CSDP operations, staffing requirements for meteorologists are not expected to vary among installations. 


\section{FUTURE WORK}

A consistent, high level of effort is needed to achieve the goals of CSDP emergency planning. Future work related to atmospheric dispersion modeling includes the actual selection of an appropriate model or models. The choice will be hampered by the difficulty in assigning priority to model requirements and by the conflicting criteria of accuracy versus timeliness. In addition, tough decisions will be required in choosing between the many multipurpose off-the-shelf models currently available, models that already have been developed specifically for the U.S. Army, or the development of new models. Future work related to meteorological monitoring includes the development of monitoring networks tailored specifically for each of the installations, and decisions regarding the inclusion of existing equipment as part of the CSDP network.

Expanding the scope of recommendations to include future work on the integrated accident assessment and warning system, it is strongly suggested that an interdisciplinary team dedicated to this effort should be designated and assembled as soon as possible. The enormous task of formulating and developing components and integrating the components into a compatible system lies ahead and is complicated by the site-specific requirements at the eight CSDP installations. Some of the components may be available in suitable form, but others are in the embryonic stage. Obviously, the task will require years of effort to complete. Because of the recommendation in this study that the meteorological towers should be operational at least 2 years before the operation of CSDP facilities, very little extra time is available. Clearly, considerable effort must be expended in a steady, timely manner to develop and implement successfully an integrated accident assessment and warning system before operation of the CSDP facilities. 


\section{REFERENCES}

Carnes, S. A. 1989. Site-Specific Emergency Response Concept Plans for the Chemical Stockpile Disposal Program: A Comparative Summary, ORNL/TM-11357, Oak Ridge National Laboratory, Oak Ridge, Tenn.

Chester, C. V. 1989. Chemical Stockpile Disposal Program Rapid Accident Assessment, ORNL/TM-11354, Oak Ridge National Laboratory, Oak Ridge, Tenn.

DOE (U.S. Department of Energy) 1987. Emergency Response and Assessment Activities at DOE Sites, CONF-860293, Proceedings of the conference held in Oak Ridge, Tenn. on February 25-26, 1986, Washington, D.C.

Draxler, R. R. 1981. "Diffusion and Transport Experiments," Chap. 8 in Atmospheric Science and Power Production, U.S. DOE/TIC-207601, U.S. Department of Energy.

EPRI (Electric Power Research Institute) 1985. Operational Validation of Gaussian and First-Order Closure Plume Models at a Moderately Complex Terrain Site, EA-3759, Project 1616.9, Palo Alto, Calif.

EPA (U.S. Environmenta' Protection Agency) 1986. Guideline on Air Quality Models (Revised), EPA-450/2-78-027R, Office of Air Quality Planning and Standards, Research Triangle Park, N.C.

EPA (U.S. Environmental Protection Agency) and DOE (U.S. Department of Energy) 1986. Determination of Atmospheric Dilution for Emergency Preparedness, A joint EPA-DOE technical workshop held in Research Triangle Park, N.C. on October 15-17, 1986, ed. Sharron Rogers, Research and Evaluation Associates, Inc.

EPA (U.S. Environmental Protection Agency) 1988. User's Guide to SDM-A Shoreline Dispersion Model, EPA-450/4-88-(017, U.S. EPA, Research Triangle Park, N.C.

Feldman, D. L. and J. E. Dobson 1990. Decision Making Technical Support Study for the U.S. Army's Chemical Stockpile Disposal Program: Enhancing Command, Control and Computer Operations at Aberdeen Proving Ground and Pine Blusf Arsenal, ORNL/TM11412, Oak Ridge National Laboratory, Oak Ridge, Tenn.

Gifford, F. A., Jr. 1968. "An Outline of Theories of Diffusion in the Lower Layers of the Atmosphere," pp. 66-116 in Meteorology and Atomic Energy-1968, ed. D. H. Slade, TID-24190, U.S. Atomic Energy Commission, National Technical Information Service.

Hanna, S. R., G. A. Briggs, and R. P. Hosker, Jr. 1982. Handbook on Atmospheric Diffusion, DOE/TIC-1122.3 (DE820()2045), U.S. Department of Energy, National Technical Information Service. 
Hanna, S. R. and P. J. Drivas 1987. Guidelines for Use of Vapor Clouc.' Dispersion Models, Center for Chemical Process Safety of the American Institute of Chemical Engineers, New York, N.Y.

Heiken, J. H. 1986. Atmospheric Tracer Technology and Applications, Noyes Publications, Park Ridge, N.J.

Lange, R. 1978. "ADPIC-A Three Dimensional Particle-In-Cell Model for the Dispersal of Atmospheric Pollutants and Its Comparison to Regional Tracer Studies," J. App. Meteor., 17, 320-29.

Lyons, W. A. 1975. "Turbulent Diffusion and Pollutant Transport in Shoreline Environments," pp. 136-208 in Lectures on Air Pollution and Environmental Impact Analyses, American Metcorological Socicty, Boston, Mass.

Pasquill, F. 1974. Almospheric Diffusion. 2nd ed. Wilcy, New York, N.Y.

Rogers, G. O., A. P. Watson, J. H. Sorensen, R. D. Sharp, and S. A. Carnes 1989. Evaluating Protective Actions for Chemical Agent Emergencies, ORNL/TM-11340, Oak Ridge National Laboratory, Oak Ridge, Tenn.

Sehmel, G. A. 1980. "Particle and Gas Dry Deposition: A Review," pp. 98.3-1011 in Atmos. Env., 14.

Sutton, O. G. 1932. "A Theory of Eddy Diffusion in the Atmosphere," Proc. R. Soc. (London), Ser. A, 135, 143.

U.S. Army 1988. Chemical Stockpile Disposal Program Final Programmatic Environmental Impact Statement, 3 vols., Program Executive Officer-Program Manager for Chemical Demilitarization, Aberdeen Proving Ground, Md.

Whitacre, C. G., J. H. Griner, M. M. Myirski, and D. W. Sloop 1987. Personal Computer Program for Chemical Hazard Prediction (D2PC), U.S. Army Chemical Research, Development and Engineering Center, CRDEC-TR-87021, Aberdeen Proving Ground, Md.

Yamada, T., M. Williams, and G. Stone 1989. Chemical Downwind Hazard Modeling Study, LA-UR-89-1061, Los Alamos National Laboratory, Los Alamos, N.M. 

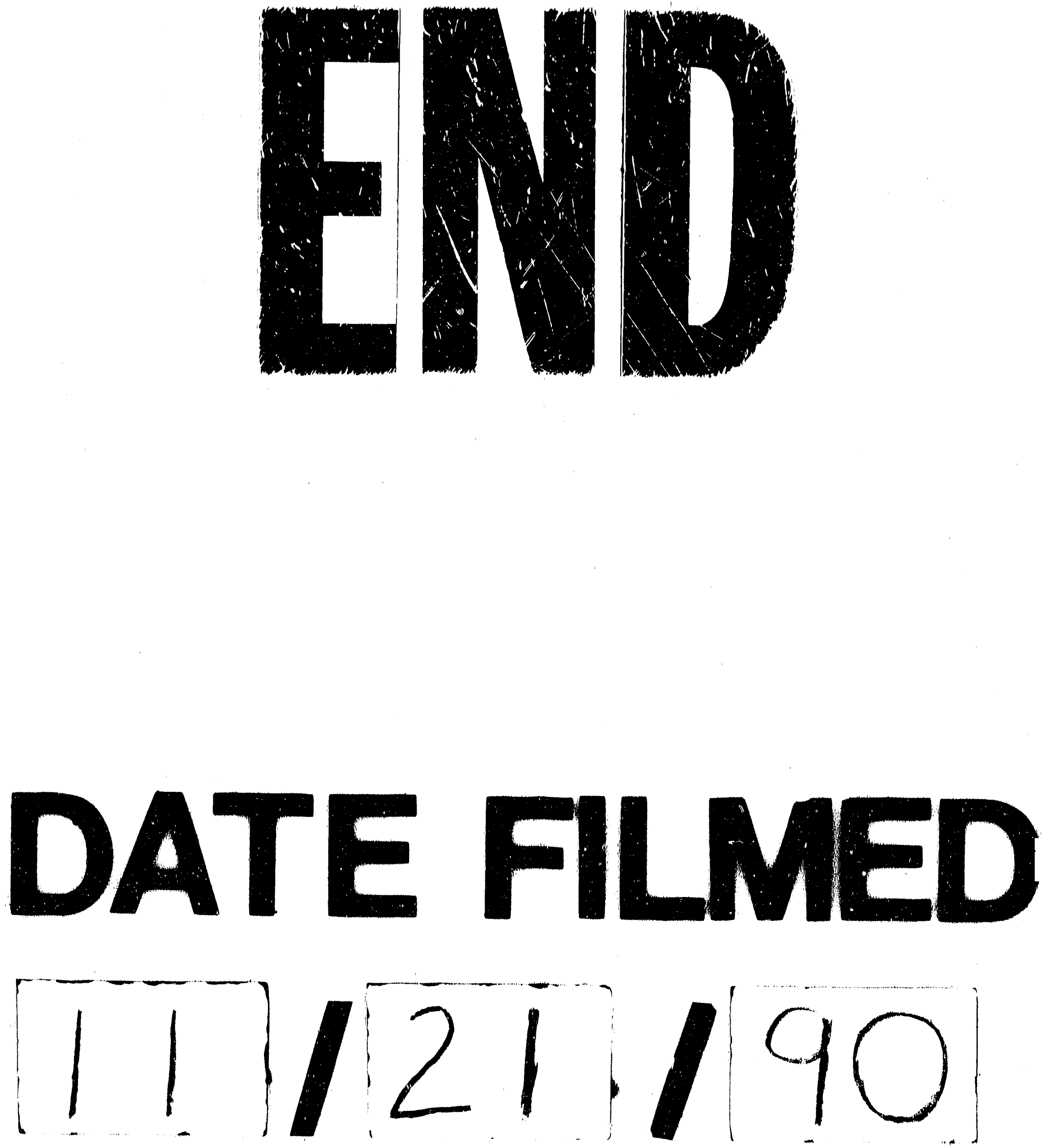
